\title{
Cloud condensation nucleus (CCN) behavior of organic aerosol particles generated by atomization of water and methanol solutions
}

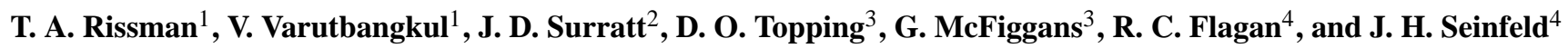 \\ ${ }^{1}$ Department of Chemical Engineering, California Institute of Technology, Pasadena, CA, USA \\ ${ }^{2}$ Department of Chemistry, California Institute of Technology, Pasadena, CA, USA \\ ${ }^{3}$ School of Earth, Atmospheric and Environmental Sciences, The University of Manchester, Manchester, UK \\ ${ }^{4}$ Departments of Chemical Engineering and Environmental Science and Engineering, California Institute of Technology, \\ Pasadena, CA, USA
}

Received: 10 November 2006 - Published in Atmos. Chem. Phys. Discuss.: 15 December 2006

Revised: 14 March 2007 - Accepted: 28 March 2007 - Published: 12 June 2007

\begin{abstract}
Cloud condensation nucleus (CCN) experiments were carried out for malonic acid, succinic acid, oxalacetic acid, DL-malic acid, glutaric acid, DL-glutamic acid monohydrate, and adipic acid, using both water and methanol as atomization solvents, at three operating supersaturations $(0.11 \%, 0.21 \%$, and $0.32 \%)$ in the Caltech three-column $\mathrm{CCN}$ instrument (CCNC3). Predictions of $\mathrm{CCN}$ behavior for five of these compounds were made using the Aerosol Diameter Dependent Equilibrium Model (ADDEM). The experiments presented here expose important considerations associated with the laboratory measurement of the $\mathrm{CCN}$ behavior of organic compounds. Choice of atomization solvent results in significant differences in $\mathrm{CCN}$ activation for some of the compounds studied, which could result from residual solvent, particle morphology differences, and chemical reactions between the particle and gas phases. Also, significant changes in aerosol size distribution occurred after classification in a differential mobility analyzer (DMA) for malonic acid and glutaric acid, preventing confident interpretation of experimental data for these two compounds. Filter analysis of adipic acid atomized from methanol solution indicates that gas-particle phase reactions may have taken place after atomization and before methanol was removed from the sample gas stream. Careful consideration of these experimental issues is necessary for successful design and interpretation of laboratory CCN measurements.
\end{abstract}

\section{Introduction}

The complex relationship between atmospheric aerosols and cloud formation, properties, and lifetime represents one of the largest uncertainties in aerosol radiative forcing of cli-

Correspondence to: J. H. Seinfeld

(seinfeld@caltech.edu) mate (IPCC, 2001). Particles that possess physical and chemical properties favorable to the condensation of water and subsequent cloud droplet growth under atmospheric conditions are termed cloud condensation nuclei (CCN). The ability of a particle of given size and composition to act as a CCN is described theoretically by Köhler theory, which incorporates the effects of particle size and chemical properties, such as aqueous solubility, molecular weight, density, and extent of dissociation in solution. The activation of inorganic salts, such as ammonium sulfate $\left(\left(\mathrm{NH}_{4}\right)_{2} \mathrm{SO}_{4}\right)$, ammonium bisulfate $\left(\mathrm{NH}_{4} \mathrm{HSO}_{4}\right)$, and sodium chloride $(\mathrm{NaCl})$, is well understood, for which measurements and predictions agree closely. After sulfate, organic material is the second most abundant component in fine aerosols (Heintzenberg, 1989; Novakov and Penner, 1993; Saxena and Hildemann, 1996; Rudich, 2003; Sun and Ariya, 2006). Properties, such as solubility, extent of dissociation, and surface activity, of ambient organic compounds vary widely and can have complex, and sometimes conflicting, effects on the ability of particles containing them to act as CCN. Whether the presence of an organic compound enhances or retards $\mathrm{CCN}$ activation depends on the chemical characteristics of the aerosol, as well as its size distribution (Rissman et al., 2004). Laboratory studies of the CCN activation of organic aerosols are an important element in evaluating the extent to which theory can predict observed behavior. Because of their prevalence in the atmosphere, the $\mathrm{CCN}$ behavior of dicarboxylic acids has been studied extensively; their CCN behavior has been found to vary widely, with some compounds exhibiting $\mathrm{CCN}$ activity near that of $\left(\mathrm{NH}_{4}\right)_{2} \mathrm{SO}_{4}$. The $\mathrm{CCN}$ behavior of some dicarboxylic acids has been successfully predicted from Köhler theory, modified to include solubility and/or surface tension effects (Cruz and Pandis, 1997; Corrigan and Novakov, 1999; Prenni et al., 2001; Giebl et al., 2002; Kumar et al., 2003; Broekhuizen et al., 2004).

Published by Copernicus Publications on behalf of the European Geosciences Union. 
Table 1. Chemical properties of compounds studied.

\begin{tabular}{|c|c|c|c|c|c|c|c|c|}
\hline Class & Compound & $\begin{array}{l}\text { Chemical } \\
\text { Formula }\end{array}$ & Chemical Structure & $\begin{array}{c}\text { Molecular } \\
\text { Weight } \\
\text { g mol }^{-1}\end{array}$ & $\begin{array}{l}\text { Density } \\
\mathrm{g} \mathrm{cm}^{-3}\end{array}$ & $\begin{array}{c}\text { Solubility, } \\
\text { g solute } \\
\mathrm{cm}^{-3} \mathrm{H}_{2} \mathrm{O} \\
\end{array}$ & $\mathrm{pKa}^{\mathrm{b}}$ & $\begin{array}{c}\text { Vapor } \\
\text { Pressure }^{c} \text {, } \\
\text { Torr }\end{array}$ \\
\hline \multirow{3}{*}{ Inorganic Salts } & $\begin{array}{l}\text { Ammonium } \\
\text { Sulfate }\end{array}$ & $\left(\mathrm{NH}_{4}\right)_{2} \mathrm{SO}_{4}$ & $\mathrm{NH}_{4}{ }^{+}$ & 132.14 & 1.770 & $0.757^{\mathrm{d}}$ & & \\
\hline & $\begin{array}{l}\text { Ammonium } \\
\text { Bisulfate }\end{array}$ & $\mathrm{NH}_{4} \mathrm{HSO}_{4}$ & $\mathrm{NH}_{4}^{+}$ & 115.11 & 1.170 & $0.359^{\mathrm{d}}$ & & \\
\hline & Sodium Chloride & $\mathrm{NaCl}$ & $\mathrm{Na}^{+} \mathrm{Cl}^{-}$ & 58.44 & 2.170 & $0.30^{\mathrm{b}}$ & & \\
\hline \multirow{7}{*}{$\begin{array}{l}\text { Organic } \\
\text { Compounds }\end{array}$} & Malonic Acid & $\mathrm{C}_{3} \mathrm{H}_{4} \mathrm{O}_{4}$ & & 104.06 & 1.619 & $0.424^{\mathrm{e}}$ & $2.83^{\mathrm{f}}$ & $4.66 \times 10^{-7}$ \\
\hline & Succinic Acid & $\mathrm{C}_{4} \mathrm{H}_{6} \mathrm{O}_{4}$ & & 118.09 & 1.572 & $\begin{array}{l}0.0835^{\mathrm{e}} \\
\left(25^{\circ} \mathrm{C}\right)\end{array}$ & 4.22 & 0.0165 \\
\hline & Oxalacetic Acid & $\mathrm{C}_{4} \mathrm{H}_{4} \mathrm{O}_{5}$ & & 132.07 & $1.631^{\mathrm{g}}$ & $0.882^{c}$ & $2.22^{\mathrm{f}}$ & $1.41 \times 10^{-5}$ \\
\hline & DL-Malic Acid & $\mathrm{C}_{4} \mathrm{H}_{6} \mathrm{O}_{5}$ & & 134.09 & $1.601^{\mathrm{g}}$ & $1.44^{\mathrm{e}}$ & $3.40^{\mathrm{f}}$ & $7.19 \times 10^{-5}$ \\
\hline & Glutaric Acid & $\mathrm{C}_{5} \mathrm{H}_{8} \mathrm{O}_{4}$ & & 132.12 & 1.429 & $\begin{array}{l}0.583^{\mathrm{e}} \\
\left(25^{\circ} \mathrm{C}\right)\end{array}$ & 4.35 & $2.23 \times 10^{-4}$ \\
\hline & $\begin{array}{l}\text { DL-Glutamic } \\
\text { Acid } \\
\text { Monohydrate }\end{array}$ & $\mathrm{C}_{5} \mathrm{H}_{9} \mathrm{O}_{4} \bullet \mathrm{H}_{2} \mathrm{O}$ & & 165.15 & $1.409^{c}$ & $\begin{array}{l}0.0235^{\mathrm{e}} \\
\left(25^{\circ} \mathrm{C}\right)\end{array}$ & $9.66^{\mathrm{a}}$ & \\
\hline & Adipic Acid & $\mathrm{C}_{6} \mathrm{H}_{10} \mathrm{O}_{4}$ & & 146.14 & 1.360 & $\begin{array}{l}0.015^{\mathrm{e}} \\
\left(15^{\circ} \mathrm{C}\right)\end{array}$ & 4.44 & $1.81 \times 10^{-5}$ \\
\hline \multicolumn{9}{|c|}{$\begin{array}{l}\text { a From CRC Handbook of Chemistry and Physics, } 84^{\text {th }} \text { Ed., unless sp } \\
\text { From } \\
\text { From Dictionary of Organic Compounds; values are at } T=25^{\circ} \mathrm{C} \text { fo } \\
\text { c Calculated using Advanced Chemistry (ACD/Labs) Software V8.14 } \\
{ }^{\mathrm{d}} \text { From Saxena and Hildemann (1996) } \\
{ }^{\mathrm{e}} \text { From CRC Handbook of Data on Organic Compounds; solubility at } \\
{ }^{\mathrm{f}} \text { From Properties of Organic Compounds; values are at } T=25^{\circ} \mathrm{C} \\
\text { g From O'Neil et al. (2001) }\end{array}$} \\
\hline
\end{tabular}

Some studies have discussed the challenges inherent to laboratory measurement of CCN activity of organic compounds. Raymond and Pandis (2002) found that some compounds were much more $\mathrm{CCN}$ active than their solubilities would suggest and attributed this to the ability of water to wet the surface of particles containing these compounds. Huff Hartz et al. (2006) atomized compounds from both water and alcohol solutions and concluded that some of the compounds are less CCN active if the particles are atomized from a nonaqueous solution. They also concluded that the ability of a compound to act as a $\mathrm{CCN}$ beyond what would be predicted based on solubility alone is a result of the existence of particles in a metastable state at low relative humidity (RH). Hori et al. (2003) found that particle drying, solute vaporization, morphology, and hydrophobicity were key factors in theoretical prediction and experimental interpretation.

In the current $\mathrm{CCN}$ laboratory study, seven organic compounds (see Table 1) are chosen based on their atmospheric relevance and/or use as surrogates in the chemical analysis and component identification of secondary organic aerosol (SOA). The CCN behavior of some of these compounds has been studied previously, and results of those studies are com- pared to the present results. The Aerosol Diameter Dependent Equilibrium Model (ADDEM; Topping et al., 2005a, b) is used to predict the CCN behavior of a subset of these compounds, for which experimental surface tension data are available. The experimental considerations mentioned above, as well as some new aspects, are discussed in detail. First, ADDEM is described, as it applies to the prediction of CCN behavior, and then the experimental studies are presented.

At the outset, the major focus of this study was twofold: (1) to meticulously measure the $\mathrm{CCN}$ behavior of particulate organic compounds; and (2) to evaluate the ability of a stateof-the-art aerosol model (ADDEM) to reproduce the observations. In the course of the experiments, it became readily apparent that the solvent used to prepare the solutions for atomization to form particles can play a profound role in the $\mathrm{CCN}$ behavior of the particle generated; mentioned above, this fact has already been noted in the literature. Because residual solvent, whether water or an organic, can influence $\mathrm{CCN}$ behavior, we also evaluate the extent to which heating of particles prior to activation alters $\mathrm{CCN}$ behavior from that in the absence of heating. A major contribution of the present 
work is a detailed evaluation of solvent effects in laboratory $\mathrm{CCN}$ studies of organic compounds.

\section{The Aerosol Diameter Dependent Equilibrium Model (ADDEM)}

\subsection{Köhler Theory}

When studying the hygroscopicity of aerosols, theories can often be divided based on whether the regime of RH is sub- or super-saturated. One can begin with the general equilibrium relation (Seinfeld and Pandis, 2006),

$$
\begin{aligned}
S & =s+1=\frac{p_{w}}{p_{\mathrm{w} \text { sat }}^{o}}=a_{w} K_{e} \\
& =a_{w} \exp \left(\frac{4 \sigma_{\mathrm{sol}} M_{w}}{R T \rho_{w} D_{\mathrm{drop}}}\right)
\end{aligned}
$$

where $S$ is the saturation ratio, $s$ is the supersaturation, $p_{w}$ is the partial pressure of water vapor, $p_{\mathrm{w}, \mathrm{sat}}^{o}$ is the saturation vapor pressure of water, $a_{w}$ is the water activity of the solution droplet, $K_{e}$ is the Kelvin term $\left\{K_{e}=\right.$ $\left.\exp \left[4 \sigma_{\mathrm{sol}} M_{w} /\left(R T \rho_{w} D_{\mathrm{drop}}\right)\right]\right\}, \sigma_{\mathrm{sol}}$ is the surface tension of the solution, $M_{w}$ is the molecular weight of water, $R$ is the universal gas constant, $T$ is temperature, $\rho_{w}$ is the density of water, and $D_{\text {drop }}$ is the droplet diameter. The water activity, $a_{w}$, of the solution droplet can be given by

$a_{w}^{-1}=1+v \Phi \frac{n_{s}}{n_{w}}$

where $v$ is the number of ions into which a solute molecule dissociates, $\Phi$ is the osmotic coefficient, $n_{s}$ is the number of moles of dissolved solute, and $n_{w}$ is the number of moles of water (Koehler et al., 2005). The logarithm of the water activity is directly related to the osmotic coefficient by (McFiggans et al., 2006):

$a_{w}=\exp \left(-\frac{v n_{s}}{n_{w}} \Phi\right)$

The number of moles of water in solution is related to the diameter of the droplet, and the number of moles of solute in the droplet is related to the number of moles originally present in the dry solute particle. If the dry solute particle is completely dissolved in the aqueous droplet, then Eq. (3) becomes

$a_{w}=\exp \left(-\frac{v \rho_{s} M_{w} d_{s}^{3}}{\rho_{w} M_{s} D_{\text {drop }}^{3}} \Phi\right)$

where $\rho_{s}$ is the density of the solute, $d_{s}$ is the diameter of the dry solute particle, and $M_{S}$ is the molecular weight of the solute. Substitution of Eq. (4) into Eq. (1) and again using the Taylor series expansion for the exponential leads to the well-known result,

$$
\begin{aligned}
s & =\frac{4 \sigma_{\text {sol }} M_{w}}{R T \rho_{w} D_{\text {drop }}}-\frac{v \rho_{s} M_{w} d_{s}^{3}}{\rho_{w} M_{s} D_{\text {drop }}^{3}} \Phi \\
& =\frac{A}{D_{\text {drop }}}-\frac{B}{D_{\text {drop }}^{3}}
\end{aligned}
$$

where $A=4 \sigma_{\mathrm{sol}} M_{w} /\left(R T \rho_{w}\right)$ and $B=v \rho_{s} M_{w} d_{s}^{3} \Phi /\left(\rho_{w} M_{s}\right)$ (Seinfeld and Pandis, 2006).

Direct use of the simplified Köhler equation (Eq. 5) for predicting behavior in the sub-saturated $\mathrm{RH}$ regime is prohibitive because it does not incorporate solid precipitation and requires modifications to be more applicable to such regions. Equilibrium thermodynamic models use the same theoretical basis on which the Köhler equation has been derived, but usually involve iterative methods combined with equilibrium constants or a direct minimization of the Gibbs free energy for relating the equilibrium water activity to composition. Most equilibrium models do not consider the influence of droplet curvature and, thus, cannot be used above $100 \%$ $\mathrm{RH}$ (or below about $100 \mathrm{~nm}$ radius). In other words, they address only the Raoult term of the Köhler equation, which is the second term of Eq. (5). An equilibrium model can evaluate $a_{w}$ directly by using the original Köhler equation (Eq. 1), combined with a method for representing the influence of curvature, either by including a surface free energy term within the Gibbs free energy summation or by using an iterative loop to solve for the Kelvin term. In this way, the entire Köhler curve can be constructed for a given particle or aerosol population. In this vein, the Aerosol Diameter Dependent Equilibrium Model (ADDEM) combines a direct minimization of the Gibbs free energy within an iterative loop that solves the original Köhler equation and allows for diameter-dependent growth factor calculations (Topping et al., 2005a, b). For treating non-ideality, both the PitzerSimonson-Clegg (Pitzer and Simonson, 1986; Clegg et al., 1992) and UNIFAC (Universal Quasichemical Functional Group Activity Coefficient; Fredenslund et al., 1975) models are employed in an additive approach for treating mixed inorganic/organic systems. The ADDEM is expanded to the supersaturated regime to include activation predictions, as well as growth factor calculations, above $100 \% \mathrm{RH}$.

\subsection{Input parameters}

For the organic compounds, three different surface tension models (S1, S2, and S3) were employed in ADDEM calculations, as well as one model that assumes the surface tension of pure water (at $298.15 \mathrm{~K}$ ). Surface tension model S1 uses the Tamura mixing rule (Tamura et al., 1955). Both models S1 and S2 are solved using the Brent method (Brent et al., 1973; see Sect. 2.3), and the S2 model uses the Suarez thermodynamic method (Suarez et al., 1989). Activities are calculated using UNIFAC with published parameters from Peng et al. (2001) for both the S2 and S3 models. The Li and $\mathrm{Lu}$ thermodynamic model ( $\mathrm{Li}$ and $\mathrm{Lu}, 2001$ ) is used to fit experimental surface tension data in model S3; saturated surface excess and adsorption constant parameters are also fit to experimental data in this model. Hence, it is expected that model S3 is the most accurate surface tension model. For the inorganic compounds, three different models were also used. The first model, S'1, is that of Chen (1994); model S'2 uses 


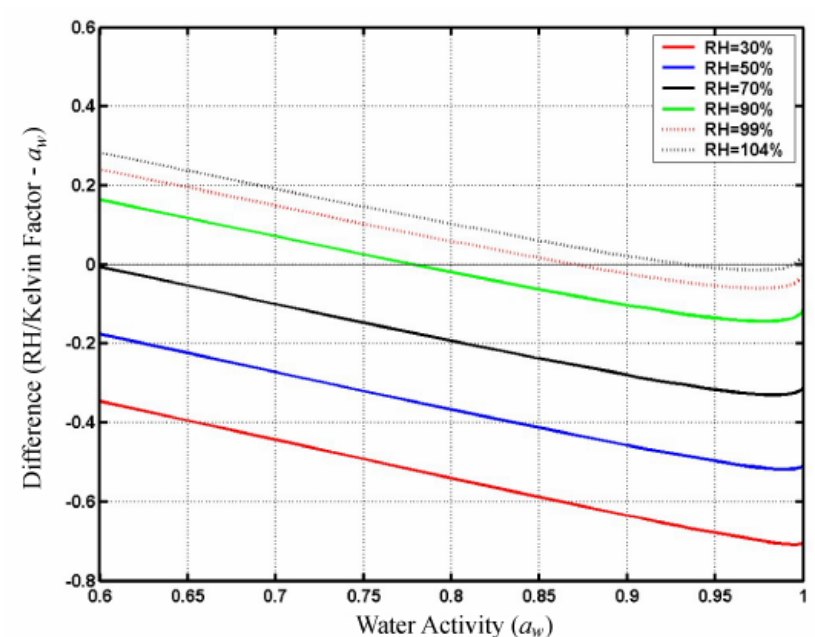

(a)

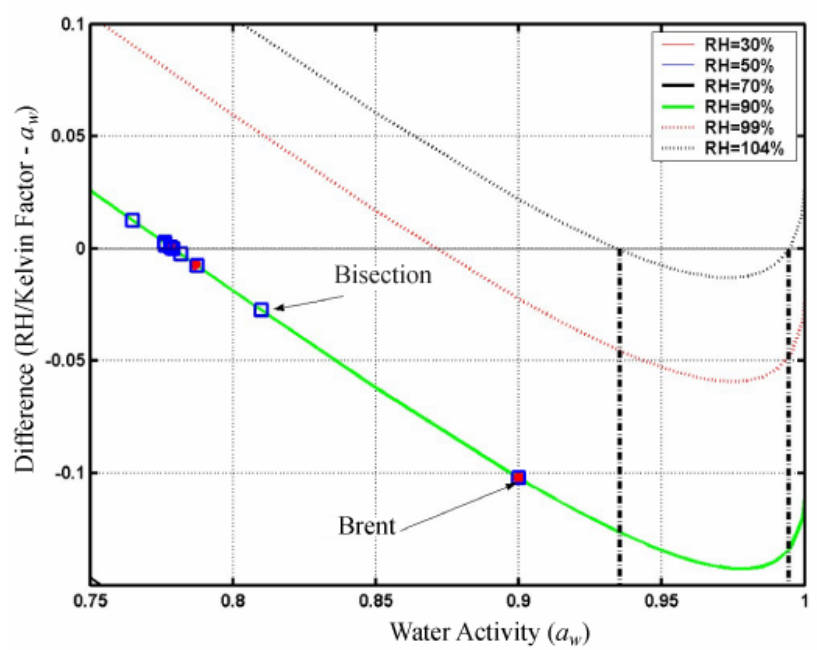

(b)

Fig. 1. (a) Difference in RH divided by the Kelvin factor and water activity $\left(a_{w}\right)$ as a function of water activity for a $10 \mathrm{~nm}$ dry diameter $\left(\mathrm{NH}_{4}\right)_{2} \mathrm{SO}_{4}$ particle at six different ambient $\mathrm{RH}$ values (given in the legend). At $90 \% \mathrm{RH}$, a water activity of 0.9 corresponds to a negative difference, and the difference value only approaches zero as the water activity is decreased to $\sim 0.78$. Hence, a $10 \mathrm{~nm}$ particle has an equilibrium water activity of $\sim 0.78$ at $90 \% \mathrm{RH}$ and has a growth factor equivalent to a bulk solution at $78 \%$ RH. (b) Magnification of panel (a) for three ambient $\mathrm{RH}$ values for a $10 \mathrm{~nm}$ diameter $\left(\mathrm{NH}_{4}\right)_{2} \mathrm{SO}_{4}$ particle at water activities greater than 0.75. Below a water activity of 0.9 the difference relationship is fairly linear, but at higher water activities the relationship becomes parabolic near the critical point. At high RH (104\%; $S=1.04 ; s=4 \%)$ there are two roots of the difference relationship for this size and composition (black dashed lines). The blue squares indicate iterations carried out using a bisection approach. The red circles indicate the more efficient Brent's method (see Sect. 2.3).

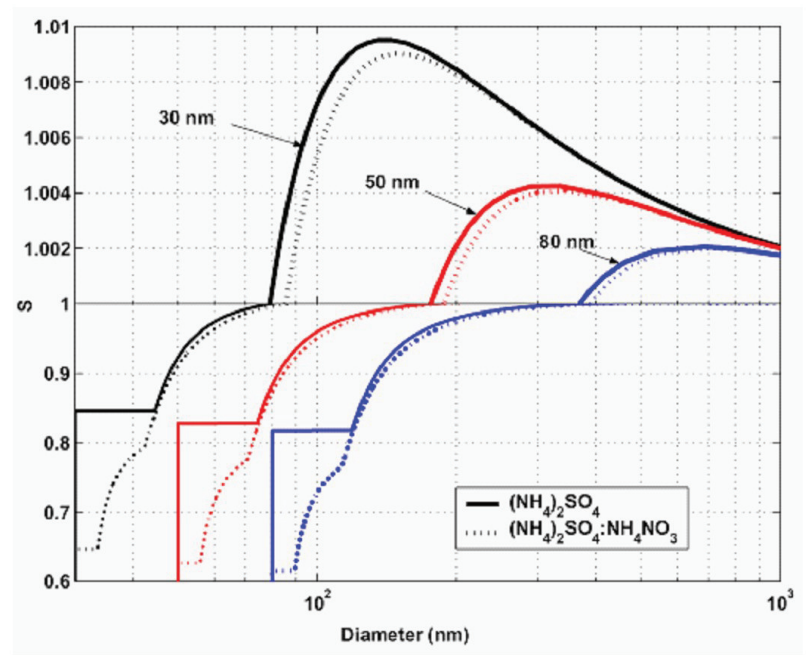

Fig. 2. Predicted Köhler curves for $\left(\mathrm{NH}_{4}\right)_{2} \mathrm{SO}_{4}$ and mixed $\left(\mathrm{NH}_{4}\right)_{2} \mathrm{SO}_{4}: \mathrm{NH}_{4} \mathrm{NO}_{3}$ paticles at 30,50 and $80 \mathrm{~nm}$ dry diameters and $298.15 \mathrm{~K}$ using ADDEM. The top half of the plot is magnified to show the critical points. The effect of solid precipitation can be seen on each curve.

the $\mathrm{Hu}$ and Lee (2004) mixing rule; and model S' 3 is the $\mathrm{Li}$ and $\mathrm{Lu}$ (2001) model. Topping et al. (2005a, b) found that growth factor calculations were particularly sensitive to the density, so the dry density is assumed in the ADDEM calculations presented here. The physical parameters used for the ADDEM calculations are given in Table 2.

\subsection{Calculations for supersaturated conditions}

For calculations above $100 \% \mathrm{RH}$, the surface energy associated with the aqueous-air interface is included within the Gibbs energy summation. It is possible to establish constraints for the water activity as calculated by the model. The difference between the energies of formation for water in the gaseous and aqueous phases dictates this condition, and, at equilibrium, the chemical potentials of water must be equal in each phase,

$\mu_{\mathrm{H}_{2} \mathrm{O}}^{o}+R T \ln \left(p_{w}\right)=\mu_{\mathrm{H}_{2} \mathrm{O}}^{*}+R T \ln \left(a_{w}\right)$

where $\mu_{\mathrm{H}_{2} \mathrm{O}}^{o}$ is the energy of formation of water in the gas phase, and $\mu_{\mathrm{H}_{2} \mathrm{O}}^{o}$ is the energy of formation in the liquid phase. Rearranging to get an expression for $\mu_{\mathrm{H}_{2} \mathrm{O}}^{o}$ gives

$\mu_{\mathrm{H}_{2} \mathrm{O}}^{o}=\mu_{\mathrm{H}_{2} \mathrm{O}}^{*}+R T \ln \left(a_{w}\right)-R T \ln \left(p_{w}\right)$

Within this computation, $\mu_{\mathrm{H}_{2} \mathrm{O}}^{o}$ can be changed to obtain a different $a_{w}$, and vice versa. In this instance, a lower $a_{w}$ $\left(\mathrm{RH}_{\text {lower }}\right)$ is required, and the new energy of formation for liquid water, $\mu_{\mathrm{H}_{2} \mathrm{O} \text {, new }}^{o}$, is given as

$\mu_{\mathrm{H}_{2} \mathrm{O} \text {,new }}^{o}=\mu_{\mathrm{H}_{2} \mathrm{O}}^{*}+R T \ln \left(\mathrm{RH}_{\text {lower }}\right)-R T \ln \left(p_{w}\right)$ 
Table 2. Physical parameters for the ADDEM calculations.

\begin{tabular}{|c|c|c|c|c|c|c|}
\hline Compound & $\begin{array}{c}\text { Molecular } \\
\text { Weight }\left(M_{s}\right) \text {, } \\
\mathrm{g} \mathrm{mol}^{-1}\end{array}$ & $\begin{array}{c}\text { Dry Density } \\
\left(\rho_{s}\right), \\
\mathrm{g} \mathrm{cm}^{-3}\end{array}$ & $\begin{array}{c}\text { Supercooled } \\
\text { Density }\left(\rho_{\mathrm{sc}}\right) \text {, } \\
\mathrm{g} \mathrm{cm}^{-3}\end{array}$ & $\begin{array}{l}\text { Molar Volume }{ }^{\mathrm{a}} \\
(v), \mathrm{cm}^{3} \mathrm{~mol}^{-1}\end{array}$ & $\begin{array}{c}\text { Critical Molar } \\
\text { Volume }{ }^{\mathrm{b}}\left(v_{c}\right) \\
\mathrm{cm}^{3} \mathrm{~mol}^{-1}\end{array}$ & $\begin{array}{c}\text { Surface Tension of } \\
\text { Pure Component } \\
{\text { dyn } \mathrm{cm}^{-1}}^{\left(\sigma_{s}\right)}\end{array}$ \\
\hline Adipic Acid & 146.14 & 1.360 & 1.250 & 149.02 & 422.65 & 40.70 \\
\hline Glutaric Acid & 132.11 & 1.429 & 1.410 & 109.97 & 366.85 & 38.88 \\
\hline Malic Acid & 134.09 & 1.595 & 1.595 & 100.57 & 325.75 & 37.51 \\
\hline Malonic Acid & 104.06 & 1.619 & 1.619 & 77.47 & 255.25 & 40.70 \\
\hline Succinic Acid & 118.09 & 1.572 & 1.572 & 93.27 & 311.05 & 40.16 \\
\hline
\end{tabular}

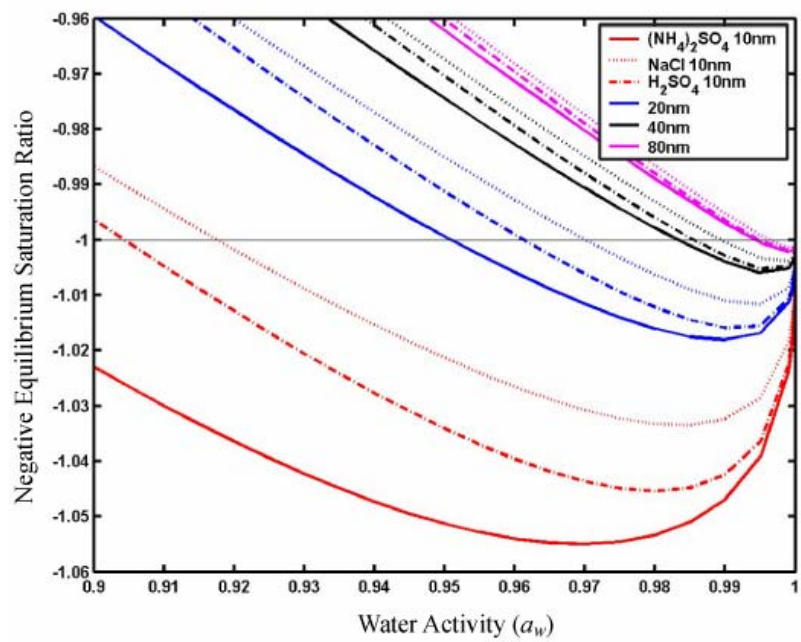

Fig. 3. Negative equilibrium saturation ratio $(S)$ as a function of water activity $\left(a_{w}\right)$ for $\left(\mathrm{NH}_{4}\right)_{2} \mathrm{SO}_{4}, \mathrm{NaCl}$ and $\mathrm{H}_{2} \mathrm{SO}_{4}$ particles at $10,20,40$ and $80 \mathrm{~nm}$. The negative value is shown because the function is minimized when finding the critical point.

Using Eq. (6), and noting that $a_{w}=\mathrm{RH}$, the relative humidity, for this case:

$$
\begin{gathered}
\mu_{\mathrm{H}_{2} \mathrm{O}, \text { new }}^{o}=R T \ln \left(\mathrm{RH}_{\text {lower }}\right)+\mu_{\mathrm{H}_{2} \mathrm{O}}^{o}-R T \ln (\mathrm{RH}) \\
=\mu_{\mathrm{H}_{2} \mathrm{O}}^{o}+R T \ln \left(\frac{\mathrm{RH}_{\text {lower }}}{\mathrm{RH}}\right)
\end{gathered}
$$

Since the ratio of $\mathrm{RH}_{\text {lower }}$ to $\mathrm{RH}$ is less than $1, \mu_{\mathrm{H}_{2} \mathrm{O} \text {,new }}^{o}$ is less than $\mu_{\mathrm{H}_{2} \mathrm{O}}^{o}$, and the magnitude is defined by the choice of $\mathrm{RH}_{\text {lower }}$ (Topping et al., 2005a, b). Boundary conditions can be placed on the Raoult curve and used to encompass the root of the difference relationship, given as

$$
\frac{\mathrm{RH}}{\exp \left(\frac{4 v \sigma_{\mathrm{sol}}}{R T D_{\mathrm{drop}}}\right)}-a_{w}=0
$$

For systems in which curvature can be neglected, the Kelvin factor is unity and Eq. (10) reduces to

$\mathrm{RH}-a_{w}=0$

To calculate the growth factor at $1 \%$ supersaturation, an upper bound on the Raoult curve multiplied by the associated

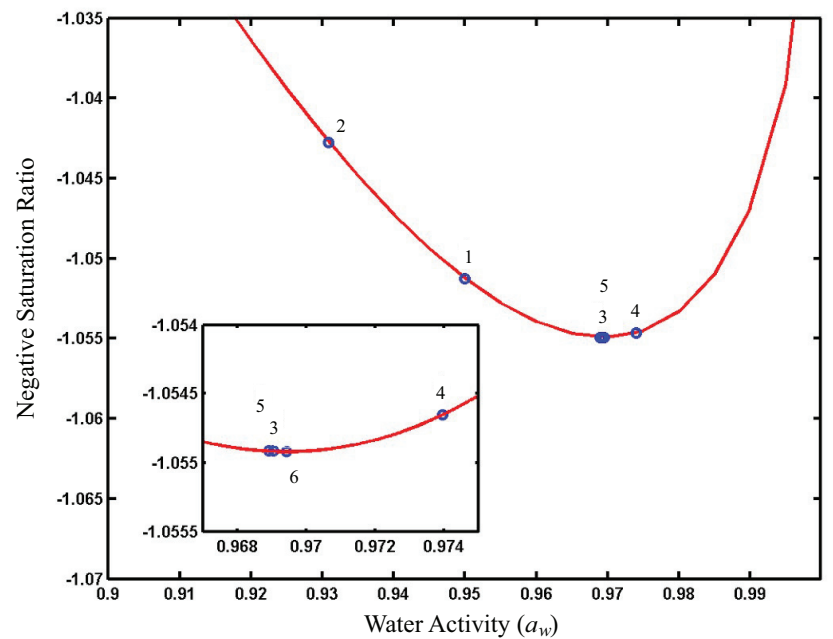

Fig. 4. Negative saturation ratio $(S)$ for a $10 \mathrm{~nm}\left(\mathrm{NH}_{4}\right)_{2} \mathrm{SO}_{4}$ particle as a function of water activity $\left(a_{w}\right)$. The blue circles highlight the iterations carried out by Brent's minimization scheme, and the iteration number is given above the blue circle. The subplot magnifies the region around the minimum point, showing its parabolic nature.

Kelvin factor may give an equilibrium RH greater than the ambient level. In other words, the left hand side of Eq. (10) is negative. Also, a lower bound on the Raoult curve multiplied by the associated Kelvin factor could give an equilibrium $\mathrm{RH}$ lower than the ambient levels. In this case, the left hand side of Eq. (10) is positive. Figure 1 shows how Eq. (10) varies by altering the water activity, adjusting $\mu_{\mathrm{H}_{2} \mathrm{O} \text {,new }}^{o}$, and varying ambient RH for a given dry size. Next, the Brent method (Brent et al., 1973), which combines bisection, secant method, and inverse quadratic interpolation, can be employed to find the root of the difference relationship. The secant method, which assumes approximate linear behavior in the region of interest, is used for all calculations; the quadratic inverse interpolation is used where possible, and bisection is used as a backup method. Brent's method takes advantage of the largely linear behavior of the difference relationship when plotted as a function of $a_{w}$.

For these calculations, the algorithm provided by Press et al. (1992) is used. The difference between this scheme and 


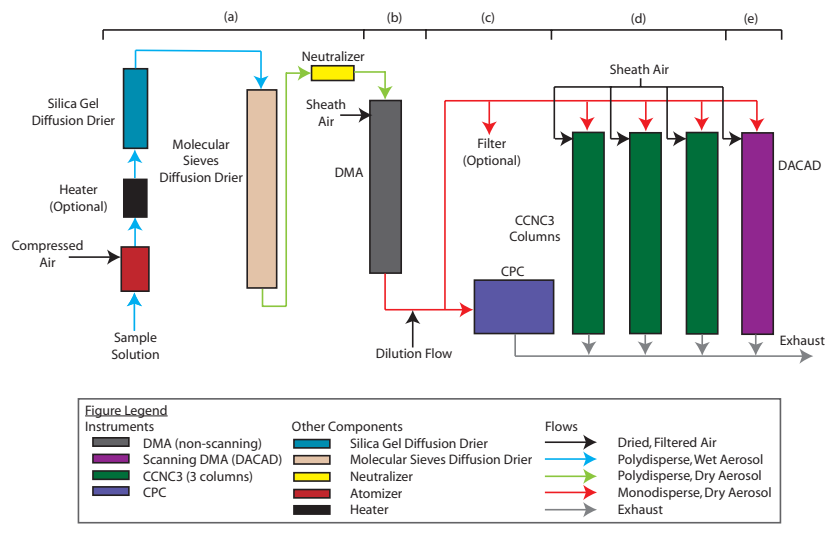

Fig. 5. Experimental System. Includes: (a) an aerosol generation system to create aerosol particles; (b) a classification DMA to classify the aerosol particles according to size (c) a CPC to count the total number of aerosol particles at a certain classified diameter; (d) the $\mathrm{CCNC} 3$ to count the number of aerosol particles that grow into droplets at the operating supersaturations of the instrument (see Table 3); (e) the DACAD to determine the size distribution of the aerosol particles entering the CCNC3.

that used for subsaturated regimes is that an initial nudge must be given before the energy minimization is carried out. In other words, the "flat" model must be kept at a water activity less than 1 . The shape of the Köhler curve above $100 \%$ $\mathrm{RH}$ dictates that there are two possible solutions, and the history of the aerosol needs to be known before appropriate boundary conditions, defined by the maximum point, can be used to refine the calculation. As shown in Fig. 1, there are two roots of Eq. (10) at an ambient RH of $104 \%$ ( $S=1.04$; $s=4 \%$ ) and for the specified size and composition. The $a_{w}$ associated with the minimum point, which is equivalent to the critical point on the Köhler curve, would be used as the upper boundary on the Raoult curve for points prior to activation and as a lower boundary for points after activation. For the former case, a lower boundary of $50 \%$ of the ambient RH should bracket the root, using an overly cautious maximum Kelvin factor of 2. For the latter scenario, a maximum water activity of 0.9999 , for example, should again be sufficient, and this is easily altered in the algorithm. An example of a full Köhler curve constructed using ADDEM is given in Fig. 2.

\subsection{Critical points}

For each growth factor calculation an ambient RH is set, and an iterative loop may ensue, such that the difference between the calculated wet diameters is minimized or instability in the growth calculations is sought (i.e. an overshoot of the critical point). A more reliable technique is to minimize the Köhler curve directly. The required one-dimensional search uses the control of $a_{w}$ through Eq. (9) to define upper and lower boundaries that bracket the critical point. Once the model is run with a given $a_{w}$, the appropriate physical information such as surface tension and density can be calculated and the point on the Köhler curve determined. Unfortunately, derivative information cannot be attained easily. As $a_{w}$ varies, so do the terms that define the Kelvin factor. The use of complex thermodynamic activity coefficient models and surface tension rules would require complicated derivative information. Fortunately, there is no need to derive such relationships and methods can be used that need only evaluations of the function, such as a basic bisection approach or Brent's method for function minimization. The latter is likely to be particularly useful since it will exploit the parabolic nature of the Köhler curve near the critical point (see Fig. 3). Figure 4 shows an example of the minimization function converging on the critical point. Since the function needs to be minimized, the negative equilibrium saturation ratio is plotted. The point labeled " 1 " is the first calculated value of the iteration halfway between the upper and lower boundaries set here as 0.9999 and 0.9. The successive iterations are also highlighted.

\section{Experimental system}

The experimental system (diagrammed in Fig. 5) includes: (a) an aerosol generation system; (b) a differential mobility analyzer (DMA) system to classify the aerosol particles; (c) a condensation particle counter (CPC; TSI, Inc., Model 3010) to count the total number of aerosol particles at a certain classified diameter; (d) the Caltech three-column CCN counter (CCNC3) to count the number of aerosol particles that grow into droplets at the operating supersaturations of the instrument; and (e) the Caltech dual automatic classified aerosol detectors (DACAD) to determine the size distribution of the aerosol particles entering the $\mathrm{CCNC} 3$. An optional heater was placed after the atomizer and prior to the driers for some experiments.

The aerosol generation and classification system consists of an atomizer, diffusion driers, a neutralizer, and a DMA. ("DMA" will be used to signify parameters associated with the DMA from the classification system; "DACAD" will be used for the DMA from the DACAD system.) The DMA has an outer radius $(R 1)$ of $0.0192 \mathrm{~m}$, an inner radius $(R 2)$ of $0.00945 \mathrm{~m}$, and a length $(L)$ of $0.4119 \mathrm{~m}$, and is operated with an aerosol sample flow rate $\left(Q_{\text {aero }}\right)$ of $0.33 \mathrm{lpm}$ and a sheath-to-aerosol ratio of 10.

For each calibration and experiment, a solution of the compound of interest was atomized to create droplets that were then dried in three diffusion driers, one filled with silica gel and the other two with molecular sieves (type 5A, 4-8 mesh). After drying, the particles were charged using a Po-210 bipolar ion source (neutralizer) and introduced into the classification DMA, which selected particles with the desired dry diameters $\left(D_{\mathrm{p}, \text { DMA }}\right)$. The resulting monodisperse aerosol 
sample was then split to the CCNC3, DACAD, and CPC. The RH in this portion of the system was kept below $5 \%$.

\subsection{Three-column $\mathrm{CCN}$ counter (CCNC3)}

The CCNC3 (described in-depth in Rissman et al., 2006) consists of three columns that operate in parallel. In this study, each column operated at a different supersaturation, the value of which was determined by calibrations with ammonium sulfate $\left(\left(\mathrm{NH}_{4}\right)_{2} \mathrm{SO}_{4}\right)$, ammonium bisulfate $\left(\mathrm{NH}_{4} \mathrm{HSO}_{4}\right)$, and sodium chloride $(\mathrm{NaCl})$. For each calibration, an aqueous solution of the inorganic salt was atomized to create droplets that were then dried and introduced into the classification system. Certain dry diameters were selected using the DMA, and the resulting monodisperse aerosol sample was split to the $\mathrm{CCNC} 3$ and $\mathrm{CPC}$. The activated ratio $(A R)$ is the ratio of the number concentration of $\mathrm{CCN}$ measured by the CCNC3 $\left(N_{\mathrm{CCN}}\right)$ to the total number concentration of particles measured by the CPC $\left(N_{\mathrm{CPC}}\right)$, and the activation diameter $\left(d_{\mathrm{act}}\right)$ is defined as the dry diameter at which $50 \%$ of the particles grow into droplets $(A R=0.5)$. To correct for the shape of the $\mathrm{NaCl}$ particles, a size-dependent shape factor $(1.08 \leq \chi \leq 1.24)$ was used (DeCarlo et al., 2004; Biskos et al., 2006). The critical supersaturations $\left(s_{c}\right)$ corresponding to dry salt particles with the classified diameters, $D_{\mathrm{p} \text {,dry }}$, were calculated using an average of the ADDEM surface tension models (S'1, S'2, S'3; not including the water surface tension model). Calibrations were performed before and after the organic experiments, and the operating supersaturation $\left(s_{\mathrm{op}}\right)$ of each column was taken from the sigmoid fit to the data of all $A R$ (from all three calibration salts and from both pre- and post-experiment calibrations) versus the $s_{c}$ cor-

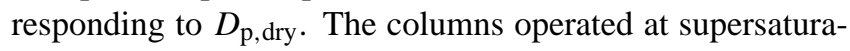
tions of $(0.11 \pm 0.03) \%,(0.21 \pm 0.02) \%$, and $(0.32 \pm 0.02) \%$, and the calibrated $d_{\text {act }}$ and the $s_{\mathrm{op}}$ values for all three columns are given in the legends in Fig. 6 and in Table 3. The error bars on the calibration curves result from the uncertainty in the diameter selected by the DMA (horizontal, $D_{\mathrm{p} \text {,dry }}$ error bars; generally taken to be $\pm 5 \%$, although calibrations indicated it to be less than $\pm 2 \%$ ) and the combined uncertainties associated with the concentrations measured by the CPC and the CCNC3 (vertical, $A R$ error bars). The uncertainty in the determination of the activation diameters (see Sect. 4) of the organic compounds for each column is taken as the average percent error in activation diameters of the inorganic salts from these calibrations: $10 \%, 7 \%$, and $9 \%$, for $s_{\mathrm{op}}=0.11 \%$, $0.21 \%$, and $0.32 \%$, respectively.

\subsection{Dual Automatic Classified Aerosol Detectors (DA- CAD)}

The Caltech DACAD has been deployed in several airborne experiments, and its characteristics are well documented (Wang et al., 2002, 2003; VanReken et al., 2003). The DACAD consists of two DMA systems operated in parallel, one of which measures the dry aerosol size distribution, while the other measures the aerosol size distribution at ambient RH by using an active RH controller (Wang et al., 2003). The main components of each measurement system are a cylindrical DMA (TSI Inc., Model 3081) and a CPC (TSI Inc., Model 3010 ), which has a $50 \%$ counting efficiency at $10 \mathrm{~nm}$. Using the scanning mobility technique (Wang and Flagan, 1990), each DMA system generates a size distribution for particle diameters from $\sim 12$ to $\sim 730 \mathrm{~nm}$ every $73.5 \mathrm{~s}$. In this study, only the dry DMA system operated in the DACAD.

\subsection{Organic compounds}

The organic compounds studied here, with some of their chemical properties, are given in Table 1. The organic compounds were selected for their atmospheric relevance or because they have structural features similar to those of SOA. The CCN behaviors of many of these compounds have been studied previously. Published CCN measurements are not available for oxalacetic acid; oxalacetic acid is a surrogate standard used in chemical analyses to identify species in SOA. Surrogate standards are selected to have similar masses, retention times (in gas or liquid chromatography methods), and functional groups as the species present in SOA. Oxalacetic acid is a good diacid standard and has been detected in cycloalkene ozonolysis experiments (Gao et al., 2004).

\subsection{Filter sampling and analysis}

Teflon filters (PALL Life Sciences, $47 \mathrm{~mm}$ diameter, $1.0 \mu \mathrm{m}$ pore size, teflon membrane) of dried particles generated by the atomization and drier system were collected and analyzed by a liquid chromatography/electrospray ionization mass spectrometry (LC/ESI-MS) technique described previously by Surratt et al. (2006). Briefly, filters were extracted in $5 \mathrm{ml}$ of High Performance Liquid Chromatography (HPLC)grade methanol by $40 \mathrm{~min}$ of sonication. The filters were then removed from the methanol sample extracts and archived at $-20^{\circ} \mathrm{C}$. Each methanol extract was blown dry under a gentle nitrogen $\left(\mathrm{N}_{2}\right)$ stream (without added heat) and then reconstituted with $300 \mu \mathrm{l}$ of a 50:50 mixture (by volume) of HPLC-grade methanol and $0.1 \%$ aqueous acetic acid solution. Laboratory control filters were extracted and treated in the same manner as the samples. Aliquots of each filter extract were analyzed by a Hewlett-Packard 1100 Series HPLC instrument, coupled with a single quadrupole mass analyzer and equipped with an electrospray ionization (ESI) source, to identify the chemical components of the atomized organic particles. Data were collected in both positive (+) and negative (-) ionization modes. An Agilent Eclipse $\mathrm{C}_{18}$ column $(3.0 \times 250 \mathrm{~mm})$ was used to separate the organic species by gradient elution (eluent B concentration increased from 5\% to $90 \%$ in $35 \mathrm{~min}$ and then decreased to $5 \%$ in $5 \mathrm{~min}$ ) before 


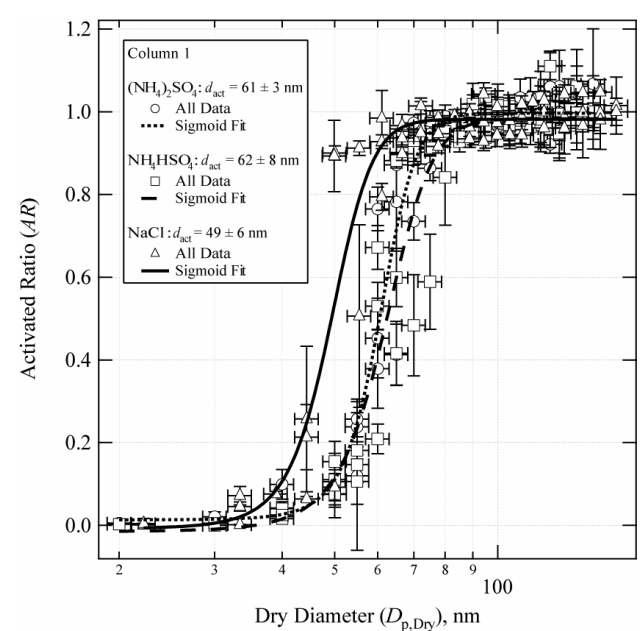

(a)

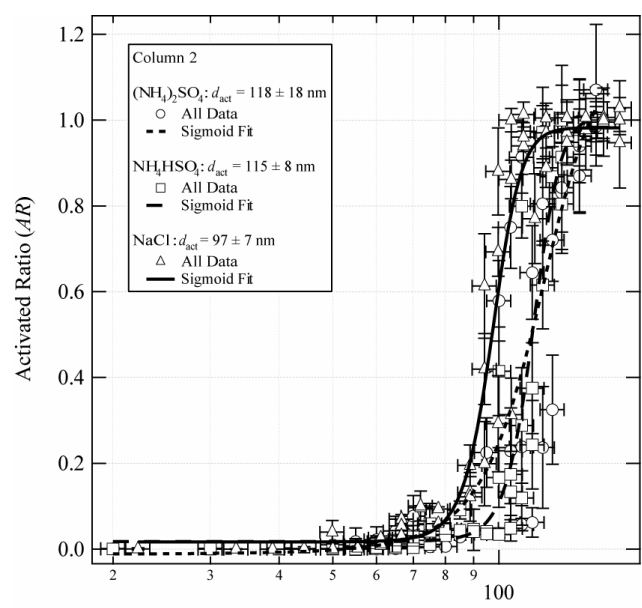

$\operatorname{Dry} \operatorname{Diameter}\left(D_{\mathrm{p}, \mathrm{Dry}}\right), \mathrm{nm}$

(c)

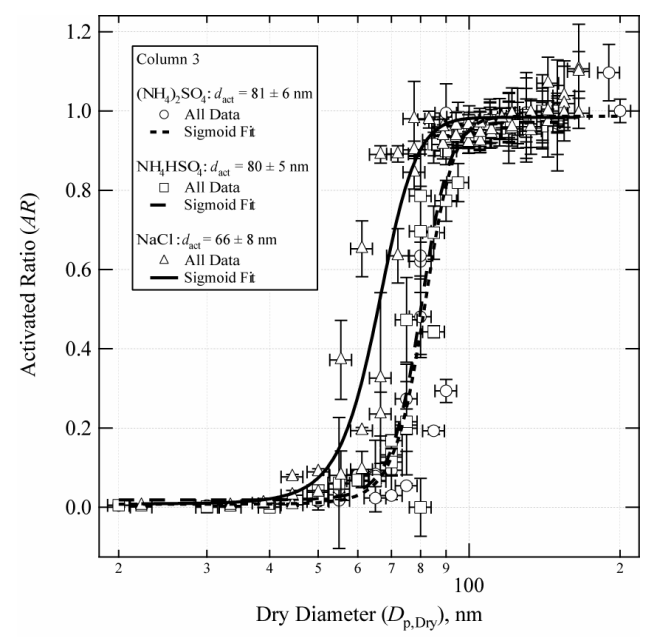

(e)

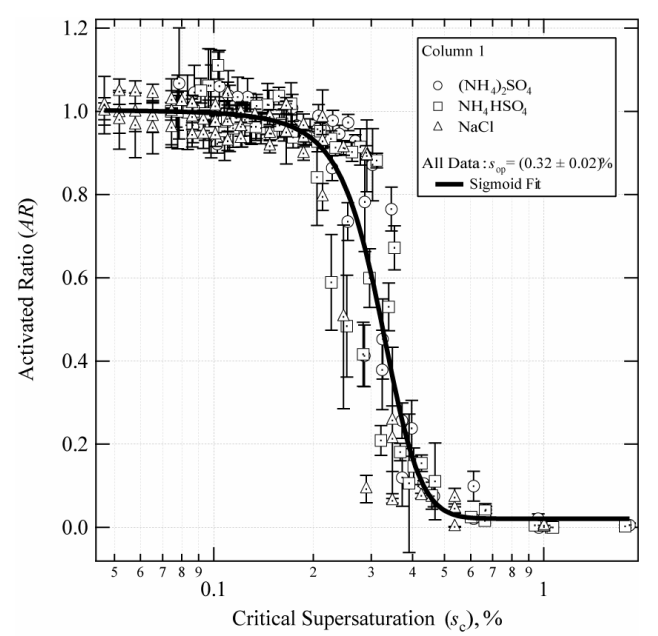

(b)

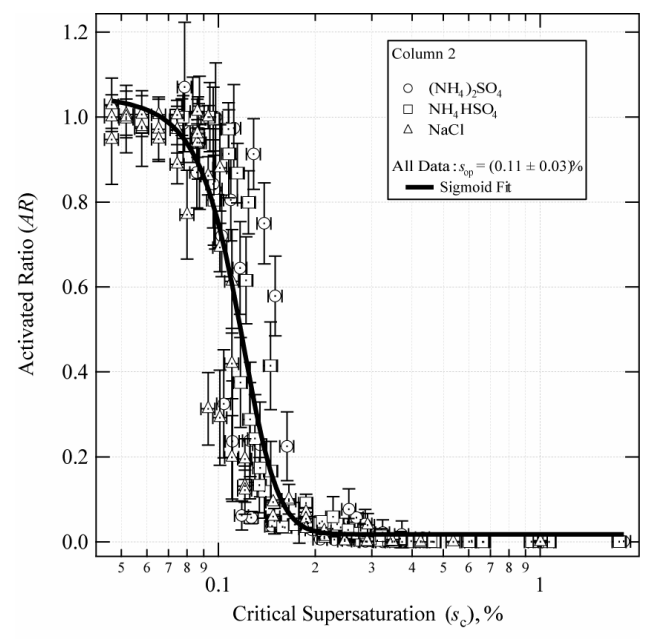

(d)

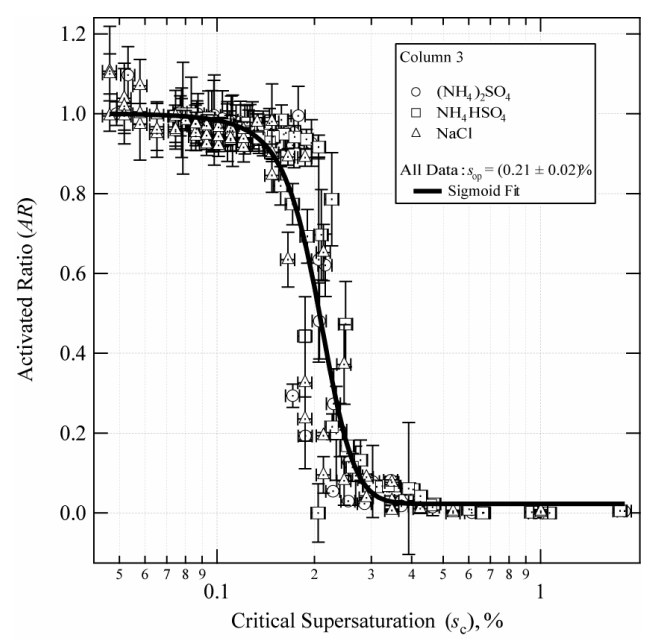

(f)

Fig. 6. Calibration curves for column 1 (panels a and b), column 2 (panels $\mathbf{c}$ and $\mathbf{d}$ ), and column 3 (panels $\mathbf{e}$ and $\mathbf{f}$ ) using $\left(\mathrm{NH}_{4}\right)_{2} \mathrm{SO}_{4}$, $\mathrm{NH}_{4} \mathrm{HSO}_{4}$, and $\mathrm{NaCl}$ as calibration salts. 
Table 3. CCNC3 calibration summary ${ }^{\mathrm{a}}$.

\begin{tabular}{|c|c|c|c|c|c|c|c|}
\hline \multirow{2}{*}{ Column } & \multicolumn{3}{|c|}{$d_{\mathrm{act}}, \mathrm{nm}$} & \multicolumn{3}{|c|}{$s_{c}, \%$} & \multirow{2}{*}{$s_{\mathrm{op}}, \%$} \\
\hline & $\left(\mathrm{NH}_{4}\right)_{2} \mathrm{SO}_{4}$ & $\mathrm{NH}_{4} \mathrm{HSO}_{4}$ & $\mathrm{NaCl}$ & $\left(\mathrm{NH}_{4}\right)_{2} \mathrm{SO}_{4}$ & $\mathrm{NH}_{4} \mathrm{HSO}_{4}$ & $\mathrm{NaCl}$ & \\
\hline 1 & $61 \pm 3$ & $62 \pm 8$ & $49 \pm 6$ & $0.33 \pm 0.04$ & $0.32 \pm 0.07$ & $0.30 \pm 0.05$ & $0.32 \pm 0.02$ \\
\hline 2 & $118 \pm 18$ & $115 \pm 8$ & $97 \pm 8$ & $0.08 \pm 0.07$ & $0.12 \pm 0.02$ & $0.11 \pm 0.03$ & $0.11 \pm 0.03$ \\
\hline 3 & $81 \pm 6$ & $80 \pm 5$ & $66 \pm 8$ & $0.21 \pm 0.03$ & $0.22 \pm 0.04$ & $0.19 \pm 0.04$ & $0.21 \pm 0.02$ \\
\hline
\end{tabular}

detection, where eluent $\mathrm{A}$ was $0.1 \%$ aqueous acetic acid and eluent B was methanol.

\subsection{Experimental considerations}

\subsubsection{Solvent effects}

Evidence has been found that organic aerosol particles generated by atomization from water solutions may retain water from the solution, even after drying to low relative humidity before size selection (Hori et al., 2003; Bilde and Svenningsson, 2004; Henning et al., 2005). This is important because the phase state of the particle is an important factor in its CCN activity. The presence of latent water in the dry particles complicates $\mathrm{CCN}$ activation experiments in two different ways: (1) incorrect size selection in the DMA (the wet particle is a different size than the dry particle would be); and (2) measured activation could depend on the amount of water present. Henning et al. (2005) showed that dry particles require higher supersaturations to activate than wet particles of the same compound. Raymond and Pandis (2002) found that some compounds were much more $\mathrm{CCN}$ active than their solubilities would suggest and attributed this to the ability of water to wet the surface of particles containing these compounds. The presence of water on the particles, even after drying to low $\mathrm{RH}$, may explain this observation.

Organic particles were generated from both methanol and water solutions for the experiments presented here. The hypothesis is that particles created from atomization of methanol solutions are easier to dry because methanol is more volatile than water and, therefore, would evaporate from the atomized droplets more easily and more quickly. Nevertheless, residual methanol left in the particles after drying could also affect apparent $\mathrm{CCN}$ activation. If a compound is more soluble in methanol than water, the presence of a small amount of methanol could facilitate the dissolution of the particle, which would facilitate condensation of water. A heater was placed after the atomizer for some experiments in an attempt to facilitate the evaporation of the atomization solvents from the particles. The heater was controlled at $40^{\circ} \mathrm{C}$ when used, but the sample stream cooled to $25^{\circ} \mathrm{C}$ before entering the $\mathrm{CCN}$ instrument.

\subsubsection{Particle evaporation}

Volatile organic particles may shrink in the system plumbing, owing to evaporation of organic material. Hori et al. (2003) hypothesized that evaporation of organic particles affected the results of their study. Evaporation, and consequent shrinking, of the organic particles after size selection by the DMA, but before being counted by the CCNC3, would cause the $d_{\text {act }}$ to appear artificially large if the actual size of the particle entering the CCNC3 was unknown. For this reason, the DACAD was included to measure the size distribution of the particles that actually entered the CCNC3. At least six up- and down-scans were measured by the DACAD for each diameter selected by the DMA. Calibrations were performed for the DMA and DACAD using polystyrene latex (PSL) spheres; diameters classified by the two systems agreed within $1.8 \%$ and $3.2 \%$ for the DACAD up- and downscans, respectively. Since the sizes of the particles may have changed inside the DMA and/or DACAD while the particles were being size classified, errors in selected diameter for the DMA have been increased to $\pm 5 \%$, which is about twice as large as that determined from calibrations with PSL spheres.

\subsubsection{Particle morphology}

The shape and morphology of the aerosol particles are important to size selection in the DMA, which is central to the CCN experiments and determination of the activation diameters. Non-spherical particles, such as $\mathrm{NaCl}$, are not properly sized in DMAs because charging efficiency and electrical mobility depend on particle morphology, mass, and cross-section (Hori et al., 2003), and a shape factor is often employed to correct for this error (Hinds, 1999). Also, observed CCN activity could be affected directly by particle morphology. Hori et al. (2004) state that solubility enhancement effects could occur when particles are non-spherical or exhibit crystallization, which would, in turn, affect the $\mathrm{CCN}$ behavior of the particles.

Different compounds could form particles of varied morphology, and particles of the same compound could exhibit different shapes, depending on differences in particle generation. A certain particle morphology for a certain organic species may exist over a range of temperatures and 


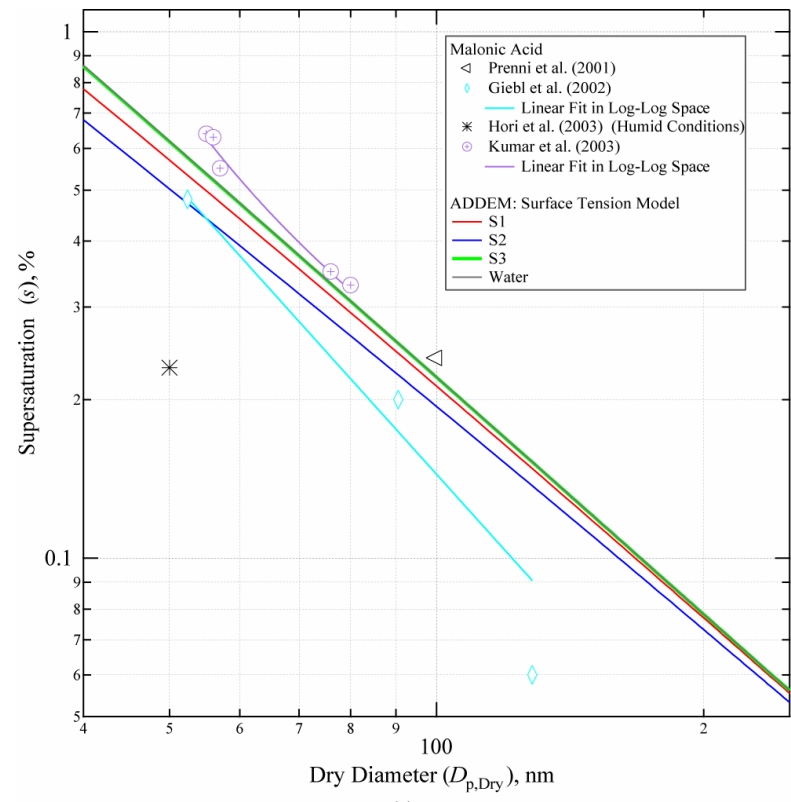

(a)

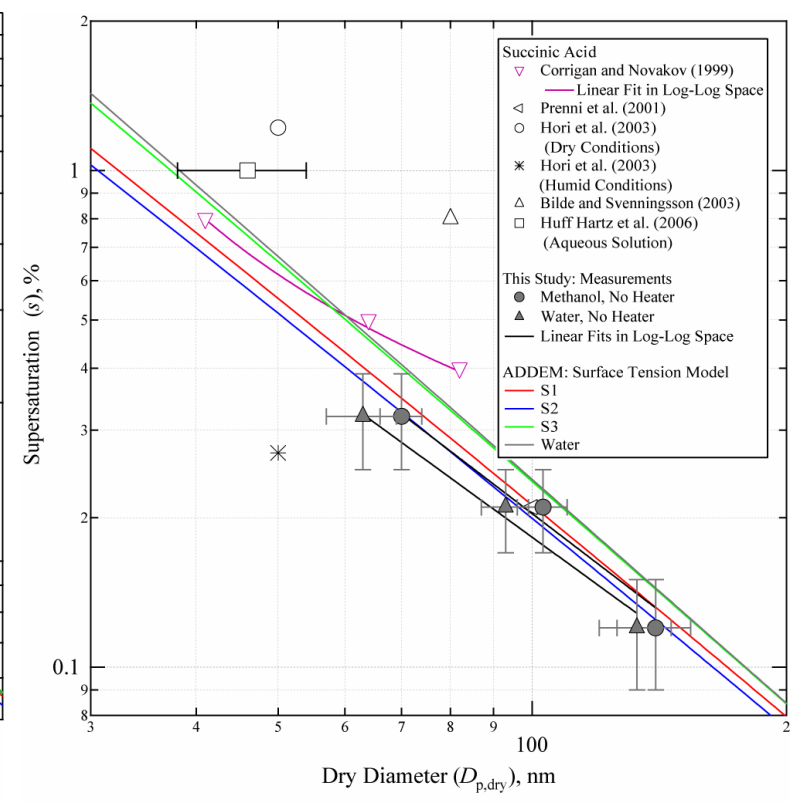

(b)

Fig. 7. Observed and predicted (ADDEM) activation behavior for (a) malonic acid and (b) succinic acid.

then change for another range of temperatures. Iskandar et al. (2003) discusses the morphology of nanoparticles created by an ultrasonic nebulizer as a function of "the sol size in the droplet, the droplet size, the viscosity of droplet, the drying temperature, the gas flow rate, and the addition of surfactant" and found that these are crucial parameters that affect the morphology of the resulting particles. The viscosity and surface tension of the droplet could be affected by the presence of an organic, regardless of the atomization solvent, and could result in different results for different organic compounds.

Organic particles generated from atomization of methanol could exhibit morphology different than those generated from water solutions because of differences in the drying rate, depending on solvent volatility and solute solubility differences, as well as other properties. Shape differences could also be caused by the temperature at which the particles are dried, since the particles would form at different drying rates. Thus, the addition of the heater after the atomizer could cause differences in morphology, and subsequently in the $\mathrm{CCN}$ activity of the compound, from improper size selection in the DMA.

\subsubsection{Gas - particle phase reactions}

Laboratory chamber studies (Surratt et al., 2006; Szmigielski et al., 2006; Angove et al., 2006) and thermodynamic calculations (Barsanti and Pankow, 2006) have revealed evidence for heterogeneous esterification reactions in SOA. In the presence of gas-phase methanol, it is possible that some or all of the organic aerosol particles in this study (specifi- cally those containing carboxylic acids) undergo esterification reactions to some extent. Esterification reactions are equilibrium reactions (Wade, 1995); therefore, the low relative humidity employed in this study likely aids this reaction. Esterification of an organic acid particle with methanol would result in the methylated ester of the organic compound and a water molecule, and the resulting ester compound could exhibit solubilities, volatilities, and other properties different than those of the parent compound. It is expected that the ester of the organic species would be less hygroscopic than the parent compound (Surratt et al., 2006). Esterification of the organic compounds could cause differences in $\mathrm{CCN}$ behavior observed for the same compound atomized from aqueous and methanol solutions. Since adipic acid exhibited the greatest differences between water and methanol atomization solutions, filter samples of adipic acid particles generated from a methanol solution were collected downstream of the aerosol generation system, and chemical analysis of the filter samples were performed. The heater was employed during the filter sampling because the greatest differences were observed for the adipic acid/methanol experiment when the heater was employed.

\section{Results and discussion}

Tables 4 through 6 give the experimental $d_{\text {act }}$ results for each compound as a ratio $(\psi)$ of $d_{\text {act }}$ for the compound to $d_{\text {act }}$ for $\left(\mathrm{NH}_{4}\right)_{2} \mathrm{SO}_{4}$ at the same $s_{\mathrm{op}}$,

$\psi\left(s_{\mathrm{op}}\right)=\frac{d_{\mathrm{act}, \text { compound }}\left(s_{\mathrm{op}}\right)}{d_{\mathrm{act},\left(\mathrm{NH}_{4}\right)_{2} \mathrm{SO}_{4}\left(s_{o}\right)}}$ 
Table 4. Ratios of measured or predicted $d_{\text {act }}$ to $d_{\text {act }}$ for $\left(\mathrm{NH}_{4}\right)_{2} \mathrm{SO}_{4}$ for $s_{\mathrm{Op}}=0.11 \%$ a

\begin{tabular}{|c|c|c|c|c|c|c|c|c|}
\hline \multirow{3}{*}{ Compound } & \multicolumn{4}{|c|}{ Measured } & \multirow{2}{*}{\multicolumn{4}{|c|}{ Predicted }} \\
\hline & \multicolumn{2}{|c|}{ Water } & \multicolumn{2}{|c|}{ Methanol } & & & & \\
\hline & $\begin{array}{l}\text { No Heater } \\
\left(d_{\mathrm{ac}}, \mathrm{nm}\right)\end{array}$ & $\begin{array}{c}\text { Heater } \\
\left(d_{\mathrm{act}}, \mathrm{nm}\right) \\
\end{array}$ & $\begin{array}{l}\text { No Heater } \\
\left(d_{\text {act }}, \mathrm{nm}\right)\end{array}$ & $\begin{array}{c}\text { Heater } \\
\left(d_{\mathrm{act}}, \mathrm{nm}\right) \\
\end{array}$ & $\begin{array}{c}\mathrm{S} 1 \\
\left(d_{\mathrm{act}}, \mathrm{nm}\right) \\
\end{array}$ & $\begin{array}{c}\mathrm{S} 2 \\
\left(d_{\mathrm{act}}, \mathrm{nm}\right) \\
\end{array}$ & $\begin{array}{c}\mathrm{S} 3 \\
\left(d_{\mathrm{act}}, \mathrm{nm}\right) \\
\end{array}$ & $\begin{array}{c}\text { Water } \\
\left(d_{\text {act }}, \mathrm{nm}\right)\end{array}$ \\
\hline Ammonium Sulfate & $\begin{array}{c}1.00 \\
(118 \pm 18)\end{array}$ & $\mathrm{NE}^{\mathrm{b}}$ & $\mathrm{NE}^{\mathrm{b}}$ & $\mathrm{NE}^{\mathrm{b}}$ & $\begin{array}{c}0.93 \\
(110)\end{array}$ & $\begin{array}{c}0.93 \\
(110)\end{array}$ & $\begin{array}{c}0.94 \\
(111)\end{array}$ & $\begin{array}{c}0.96 \\
(113)\end{array}$ \\
\hline Ammonium Bisulfate & $\begin{array}{c}0.97 \pm 0.16 \\
(115 \pm 8)\end{array}$ & $N E^{b}$ & $\mathrm{NE}^{\mathrm{b}}$ & $\mathrm{NE}^{\mathrm{b}}$ & $\begin{array}{c}0.95 \\
(112)\end{array}$ & $\begin{array}{c}0.95 \\
(112)\end{array}$ & $\begin{array}{c}0.95 \\
(112)\end{array}$ & $\begin{array}{c}0.95 \\
(112)\end{array}$ \\
\hline Sodium Chloride & $\begin{array}{c}0.80 \pm 0.14 \\
(97 \pm 8)\end{array}$ & $N E^{b}$ & $\mathrm{NE}^{\mathrm{b}}$ & $N E^{b}$ & $\begin{array}{l}0.75 \\
(89)\end{array}$ & $\begin{array}{l}0.75 \\
(89)\end{array}$ & $\begin{array}{l}0.75 \\
(89)\end{array}$ & $\begin{array}{l}0.76 \\
(90)\end{array}$ \\
\hline Malonic Acid & $\mathrm{ND}^{\mathrm{b}}$ & $\mathrm{ND}^{\mathrm{b}}$ & $\mathrm{ND}^{\mathrm{b}}$ & $\mathrm{ND}^{\mathrm{b}}$ & $\begin{array}{c}1.32 \\
(156)\end{array}$ & $\begin{array}{c}1.23 \\
(145)\end{array}$ & $\begin{array}{c}1.32 \\
(156)\end{array}$ & $\begin{array}{l}1.29 \\
(152)\end{array}$ \\
\hline Succinic Acid & $\begin{array}{c}1.13 \pm 0.20 \\
(133 \pm 13)\end{array}$ & $\mathrm{NE}^{\mathrm{b}}$ & $\begin{array}{c}1.19 \pm 0.22 \\
(140 \pm 14)\end{array}$ & $\mathrm{NE}^{\mathrm{b}}$ & $\begin{array}{c}1.31 \\
(154)\end{array}$ & $\begin{array}{c}1.25 \\
(148)\end{array}$ & $\begin{array}{c}1.41 \\
(166)\end{array}$ & $\begin{array}{c}1.39 \\
(164)\end{array}$ \\
\hline Oxalacetic Acid & $\begin{array}{l}1.02 \pm 0.19 \\
(120 \pm 12)\end{array}$ & $\mathrm{NE}^{\mathrm{b}}$ & $\begin{array}{c}1.13 \pm 0.20 \\
(133 \pm 13)\end{array}$ & $\mathrm{NE}^{\mathrm{b}}$ & $\mathrm{NM}^{\mathrm{b}}$ & $\mathrm{NM}^{\mathrm{b}}$ & $\mathrm{NM}^{\mathrm{b}}$ & $\mathrm{NM}^{\mathrm{b}}$ \\
\hline DL-Malic Acid & $\begin{array}{c}1.14 \pm 0.21 \\
(135 \pm 14)\end{array}$ & $\mathrm{NE}^{\mathrm{b}}$ & $\begin{array}{c}1.17 \pm 0.21 \\
(138 \pm 14)\end{array}$ & $\mathrm{NE}^{\mathrm{b}}$ & $\begin{array}{c}1.35 \\
(159)\end{array}$ & $\begin{array}{c}1.27 \\
(150)\end{array}$ & $\begin{array}{c}1.46 \\
(172)\end{array}$ & $\begin{array}{c}1.46 \\
(172)\end{array}$ \\
\hline Glutaric Acid & $\mathrm{ND}^{\mathrm{b}}$ & $\mathrm{ND}^{\mathrm{b}}$ & $\mathrm{ND}^{\mathrm{b}}$ & $\mathrm{ND}^{\mathrm{b}}$ & $\begin{array}{c}1.28 \\
(151)\end{array}$ & $\begin{array}{c}1.28 \\
(151)\end{array}$ & $\begin{array}{l}1.47 \\
(174)\end{array}$ & $\begin{array}{l}1.47 \\
(174)\end{array}$ \\
\hline DL-Glutamic Acid Monohydrate & $\begin{array}{c}1.18 \pm 0.22 \\
(139 \pm 14)\end{array}$ & $\mathrm{NE}^{\mathrm{b}}$ & $\begin{array}{c}1.15 \pm 0.21 \\
(136 \pm 14)\end{array}$ & $\mathrm{NE}^{\mathrm{b}}$ & $\mathrm{NM}^{\mathrm{b}}$ & $\mathrm{NM}^{\mathrm{b}}$ & $\mathrm{NM}^{\mathrm{b}}$ & $\mathrm{NM}^{\mathrm{b}}$ \\
\hline Adipic Acid & $\begin{array}{c}2.22 \pm 0.40 \\
(267 \pm 26)\end{array}$ & $\begin{array}{l}1.97 \pm 0.36 \\
(232 \pm 23)\end{array}$ & $\begin{array}{c}1.47 \pm 0.27 \\
(174 \pm 17)\end{array}$ & $\begin{array}{c}1.96 \pm 0.36 \\
(231 \pm 23)\end{array}$ & $\begin{array}{c}1.28 \\
(151)\end{array}$ & $\begin{array}{c}1.17 \\
(138)\end{array}$ & $\begin{array}{c}1.36 \\
(160)\end{array}$ & $\begin{array}{c}1.49 \\
(176)\end{array}$ \\
\hline
\end{tabular}

as well as the actual experimental $d_{\text {act }}$. In the absence of heating, values for $\psi$ range from 1.02-2.22 (120-267 nm), 1.15$3.21(93-257 \mathrm{~nm})$, and $1.03-3.62(63-221 \mathrm{~nm})$ for $s_{\mathrm{op}}=0.11$, 0.21 , and $0.32 \%$, respectively, for organic particles generated with aqueous solutions, and 1.13-1.47 (133-174 nm), 1.10$1.56(89-126 \mathrm{~nm})$, and $1.02-1.74(62-106 \mathrm{~nm})$ for methanol solutions. With the heater in place, adipic acid values for $\psi$ are $1.97(232 \mathrm{~nm}), 2.60(213 \mathrm{~nm})$, and $3.25(198 \mathrm{~nm})$ for $s_{\mathrm{op}}=0.11,0.21$, and $0.32 \%$, respectively, for organic particles generated with aqueous solutions. For methanol solutions, values of $\psi$ for adipic acid are $1.96(231 \mathrm{~nm}), 2.57$ $(208 \mathrm{~nm})$, and $2.90(177 \mathrm{~nm})$ for $s_{\mathrm{op}}=0.11,0.21$, and $0.32 \%$, respectively, with the heater in place. In some cases the observations are not uniform for the different operating supersaturations, even under the same experimental conditions. These differences among operating supersaturations could be caused by the aforementioned experimental considerations, especially because the effects are expected to be sizedependent.

ADDEM predictions were performed for those systems for which experimental surface tension data are available for model S3 (see Sect. 2.2). The model predictions of $d_{\mathrm{act}}$ for $\left(\mathrm{NH}_{4}\right)_{2} \mathrm{SO}_{4}, \mathrm{NH}_{4} \mathrm{HSO}_{4}, \mathrm{NaCl}$, succinic acid, malonic acid, adipic acid, glutaric acid, malic acid, and oxalic acid are also included in Tables 4 through 6 . These systems have also been validated for calculations of $a_{w}$, which results in a direct comparison with the fundamental Köhler equation without being subject to many unknowns. Models S1 and S2 require variables that have to be calculated for most systems of atmospheric interest. The ADDEM and experimental results for adipic acid, glutaric acid, malic acid, malonic acid, oxalic acid, and succinic acid from this study, as well as data from previous studies (previous studies are from aqueous solutions unless otherwise noted), are discussed in Sect. 4.4. From the ADDEM results, $\psi$ values for the listed organic compounds range from $1.17-1.49(138-176 \mathrm{~nm}), 1.15-1.51$ $(93-122 \mathrm{~nm})$, and $1.15-1.52(70-93 \mathrm{~nm})$ for $s_{\mathrm{op}}=0.11,0.21$, and $0.32 \%$, respectively. Figures 7 through 10 and Table 7 summarize the measurements and predictions from the current study and compare these results to those from past studies.

\subsection{Changes in aerosol size distribution}

Size distribution changes were observed after size selection in the classification DMA. For most compounds, slight particle shrinking was observed in DACAD data. For malonic acid and glutaric acid, size distributions were broadened or multipeaked by the time they were measured in the DACAD. DMA and DACAD PSL calibrations indicate that size classification resulted in very sharp peaks, defined here as having a standard deviation $(\sigma)$ less than 0.10 . If the only process occurring for malonic and glutaric acids was evaporation of organic material from the particles, the DACAD size distribution would still show only one, sharp peak but at a smaller diameter because the same-sized particles would evaporate at 
Table 5. Ratios of measured or predicted $d_{\text {act }}$ to $d_{\text {act }}$ for $\left(\mathrm{NH}_{4}\right)_{2} \mathrm{SO}_{4}$ for $s_{\mathrm{op}}=0.21 \%$ a

\begin{tabular}{|c|c|c|c|c|c|c|c|c|}
\hline \multirow{3}{*}{ Compound } & \multicolumn{4}{|c|}{ Measured } & \multirow{2}{*}{\multicolumn{4}{|c|}{ Predicted }} \\
\hline & \multicolumn{2}{|c|}{ Water } & \multicolumn{2}{|c|}{ Methanol } & & & & \\
\hline & $\begin{array}{l}\text { No Heater } \\
\left(d_{\mathrm{act}}, \mathrm{nm}\right)\end{array}$ & $\begin{array}{c}\text { Heater } \\
\left(d_{\mathrm{act}}, \mathrm{nm}\right)\end{array}$ & $\begin{array}{l}\text { No Heater } \\
\left(d_{\mathrm{act}}, \mathrm{nm}\right)\end{array}$ & $\begin{array}{c}\text { Heater } \\
\left(d_{\mathrm{act}}, \mathrm{nm}\right)\end{array}$ & $\begin{array}{c}\mathrm{S} 1 \\
\left(d_{\mathrm{act}}, \mathrm{nm}\right)\end{array}$ & $\begin{array}{c}\mathrm{S} 2 \\
\left(d_{\mathrm{act}}, \mathrm{nm}\right)\end{array}$ & $\begin{array}{c}\mathrm{S} 3 \\
\left(d_{\mathrm{act}}, \mathrm{nm}\right)\end{array}$ & $\begin{array}{c}\text { Water } \\
\left(d_{\mathrm{act}}, \mathrm{nm}\right)\end{array}$ \\
\hline Ammonium Sulfate & $\begin{array}{c}1.00 \\
(81 \pm 6)\end{array}$ & $N E^{b}$ & $\mathrm{NE}^{\mathrm{b}}$ & $\mathrm{NE}^{\mathrm{b}}$ & $\begin{array}{l}0.96 \\
(78)\end{array}$ & $\begin{array}{l}0.96 \\
(78)\end{array}$ & $\begin{array}{l}0.96 \\
(78)\end{array}$ & $\begin{array}{l}0.98 \\
(79)\end{array}$ \\
\hline Ammonium Bisulfate & $\begin{array}{c}0.99 \pm 0.10 \\
(80 \pm 5)\end{array}$ & $N E^{b}$ & $N E^{b}$ & $N E^{b}$ & $\begin{array}{l}0.96 \\
(78)\end{array}$ & $\begin{array}{l}0.96 \\
(78)\end{array}$ & $\begin{array}{l}0.95 \\
(78)\end{array}$ & $\begin{array}{l}0.96 \\
(78)\end{array}$ \\
\hline Sodium Chloride & $\begin{array}{c}0.79 \pm 0.11 \\
(66 \pm 8)\end{array}$ & $N E^{b}$ & $N E^{b}$ & $N E^{b}$ & $\begin{array}{l}0.77 \\
(62) \\
\end{array}$ & $\begin{array}{l}0.77 \\
(62) \\
\end{array}$ & $\begin{array}{l}0.77 \\
(62) \\
\end{array}$ & $\begin{array}{l}0.77 \\
(62) \\
\end{array}$ \\
\hline Malonic Acid & $\mathrm{ND}^{\mathrm{b}}$ & $\mathrm{ND}^{\mathrm{b}}$ & $\mathrm{ND}^{\mathrm{b}}$ & $\mathrm{ND}^{\mathrm{b}}$ & $\begin{array}{c}1.28 \\
(104)\end{array}$ & $\begin{array}{l}1.19 \\
(96)\end{array}$ & $\begin{array}{c}1.31 \\
(106)\end{array}$ & $\begin{array}{c}1.26 \\
(102)\end{array}$ \\
\hline Succinic Acid & $\begin{array}{c}1.15 \pm 0.11 \\
(93 \pm 6)\end{array}$ & $N E^{b}$ & $\begin{array}{c}1.27 \pm 0.13 \\
(103 \pm 7)\end{array}$ & $N E^{b}$ & $\begin{array}{c}1.26 \\
(102)\end{array}$ & $\begin{array}{l}1.20 \\
(97)\end{array}$ & $\begin{array}{c}1.38 \\
(112)\end{array}$ & $\begin{array}{c}1.38 \\
(112)\end{array}$ \\
\hline Oxalacetic Acid & $\begin{array}{c}1.21 \pm 0.12 \\
(98 \pm 7)\end{array}$ & $N E^{b}$ & $\begin{array}{c}1.19 \pm 0.12 \\
(96 \pm 7)\end{array}$ & $N E^{b}$ & $\mathrm{NM}^{\mathrm{b}}$ & $\mathrm{NM}^{\mathrm{b}}$ & $\mathrm{NM}^{\mathrm{b}}$ & $\mathrm{NM}^{\mathrm{b}}$ \\
\hline DL-Malic Acid & $\begin{array}{c}1.25 \pm 0.13 \\
(101 \pm 7)\end{array}$ & $N E^{b}$ & $\begin{array}{c}1.10 \pm 0.11 \\
(89 \pm 6)\end{array}$ & $N E^{b}$ & $\begin{array}{c}1.28 \\
(104)\end{array}$ & $\begin{array}{l}1.21 \\
(98)\end{array}$ & $\begin{array}{c}1.43 \\
(116)\end{array}$ & $\begin{array}{c}1.43 \\
(116)\end{array}$ \\
\hline Glutaric Acid & $\mathrm{ND}^{\mathrm{b}}$ & $\mathrm{ND}^{\mathrm{b}}$ & $\mathrm{ND}^{\mathrm{b}}$ & $\mathrm{ND}^{\mathrm{b}}$ & $\begin{array}{c}1.24 \\
(100)\end{array}$ & $\begin{array}{c}1.23 \\
(100)\end{array}$ & $\begin{array}{c}1.47 \\
(119)\end{array}$ & $\begin{array}{l}1.47 \\
(119)\end{array}$ \\
\hline DL-Glutamic Acid Monohydrate & $\begin{array}{c}1.27 \pm 0.13 \\
(103 \pm 7)\end{array}$ & $N E^{b}$ & $\begin{array}{c}1.17 \pm 0.12 \\
(95 \pm 7)\end{array}$ & $\mathrm{NE}^{\mathrm{b}}$ & $\mathrm{NM}^{\mathrm{b}}$ & $\mathrm{NM}^{\mathrm{b}}$ & $\mathrm{NM}^{\mathrm{b}}$ & $\mathrm{NM}^{\mathrm{b}}$ \\
\hline Adipic Acid & $\begin{array}{c}3.21 \pm 0.32 \\
(257 \pm 18) \\
\end{array}$ & $\begin{array}{c}2.60 \pm 0.27 \\
(213 \pm 15) \\
\end{array}$ & $\begin{array}{c}1.56 \pm 0.16 \\
(126 \pm 9)\end{array}$ & $\begin{array}{c}2.57 \pm 0.26 \\
(208 \pm 14) \\
\end{array}$ & $\begin{array}{c}1.26 \\
(102) \\
\end{array}$ & $\begin{array}{l}1.15 \\
(93) \\
\end{array}$ & $\begin{array}{c}1.32 \\
(107) \\
\end{array}$ & $\begin{array}{c}1.51 \\
(122) \\
\end{array}$ \\
\hline
\end{tabular}

the same rate, as was observed for the other compounds. The multiple peaks could be caused by the presence of doubly charged particles, however doubly charged particles are usually not observed to this extent. In this case, the peaks measured by the DACAD would represent particles of two different diameters, selected at the same mobility by the size selection DMA, that shrank at different rates before they were measured in the DACAD. Multiple peaks were only observed for malonic and glutaric acids, which may indicate a dependence of particle charging or other size-altering processes on chemical composition.

Figure 11 shows examples of shrinking and size distribution changes for the given diameter particle, size-selected by the DMA, for malonic acid. The size distribution shown for the particle with $D_{\mathrm{p}, \mathrm{DMA}}=300 \mathrm{~nm}$ is indicative of a "sharp" size distribution, with $\sigma<0.10$. For the compounds for which DACAD size distributions have a standard deviation less than or equal to 0.10 , the DMA selected $D_{\mathrm{p}, \text { DMA }}$ was replaced with the DACAD measured diameter $\left(D_{\mathrm{p}, \mathrm{DACAD}}\right)$ in the analysis. (In some plots and tables, the dry diameter is shown as a generic $D_{\mathrm{p}, \text { dry }}$. For inorganic compounds, $D_{\mathrm{p} \text {,dry }}$ is $D_{\mathrm{p}, \text { DMA }}$; for organic compounds, $D_{\mathrm{p}, \mathrm{DACAD}}$. Also, $s$ refers to $s_{\mathrm{op}}$ for experimental results and $s_{c}$ for model predictions.) Table 8 gives the activation diameters before and after DACAD dry diameter corrections.

Confident, detailed data analysis and corrections were not possible for malonic acid and glutaric acid because the data set was convoluted by the possible presence of both an excessive amount of doubly charged particles and other issues. It was difficult to determine with a high degree of scientific certainty which size-altering processes, such as doubly charged particles, collapsed particles, or trapped solvent, contributed to the size distribution changes. For this reason, $d_{\text {act }}$ values are not presented for malonic and glutaric acids. In future studies, such data could be better understood by using a second neutralizer prior to measurement in the second DMA system. A second neutralizer may have provided a better indication of the correct sizes of the particles and facilitated $\mathrm{CCN}$ data analysis and corrections.

\subsection{Solvent choice}

For some compounds, the experimentally determined activation diameters varied, depending on whether the particles were generated from water or methanol solutions. Differences between methanol and water $\psi$ values were within experimental error for succinic acid, oxalacetic acid, and DLglutamic acid at all three operating supersaturations, and for DL-malic acid at $s_{\mathrm{op}}=0.11 \%$ and $0.32 \%$. Greater $\psi$ values were measured for aqueous solutions of DL-malic acid at $s_{\mathrm{op}}=0.21 \%$ and adipic acid at all three operating supersaturations. The most pronounced differences were observed for adipic acid, for which $\psi$ values for water and methanol solutions differed by as much as $66 \%$. As will be discussed in Sect. 4.4.3, the choice of atomization solvent could affect the 


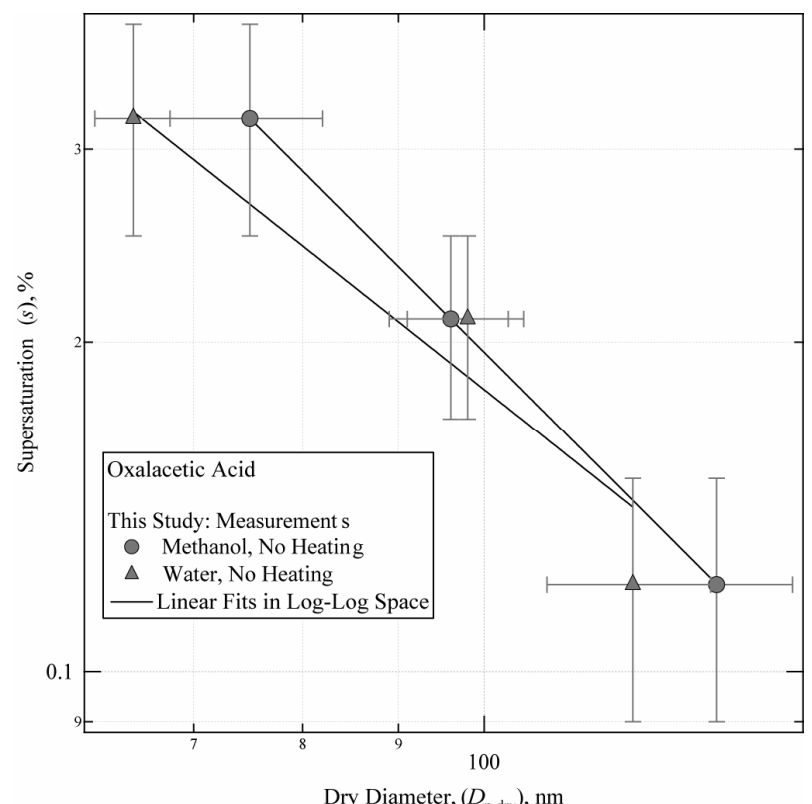

(a)

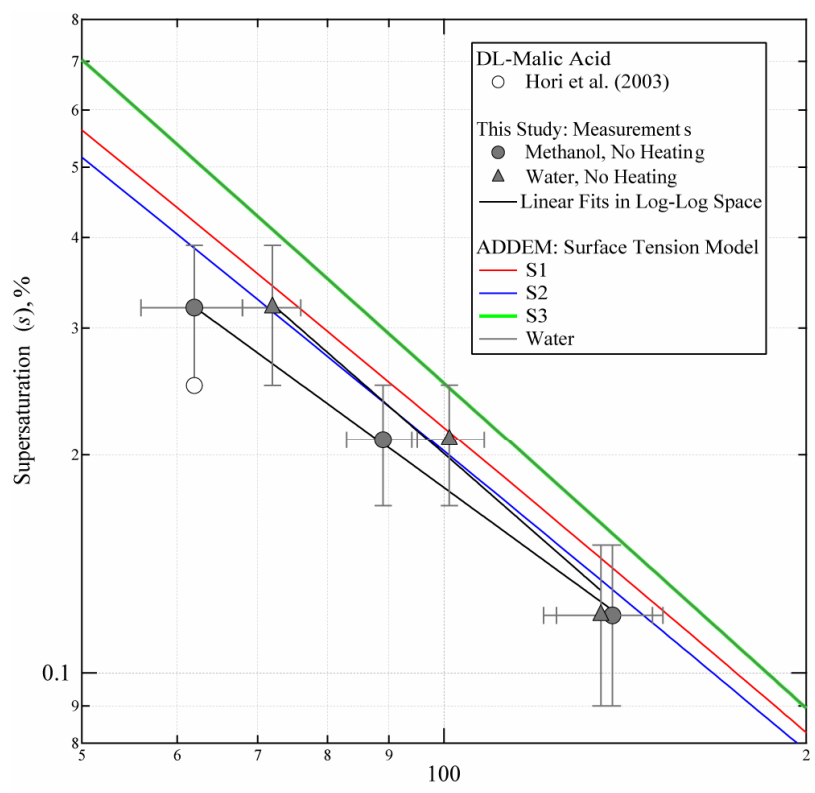

Dry Diameter $\left(D_{\mathrm{p}, \mathrm{dry}}\right), \mathrm{nm}$

(b)

Fig. 8. Observed and predicted (ADDEM) activation behavior for (a) oxalacetic acid and (b) DL-malic acid.

resulting morphology of the generated particles and, consequently, the size selection in the DMA. Differences observed in the $\mathrm{CCN}$ activity for particles atomized from aqueous versus methanol solutions could be explained by this phenomenon.

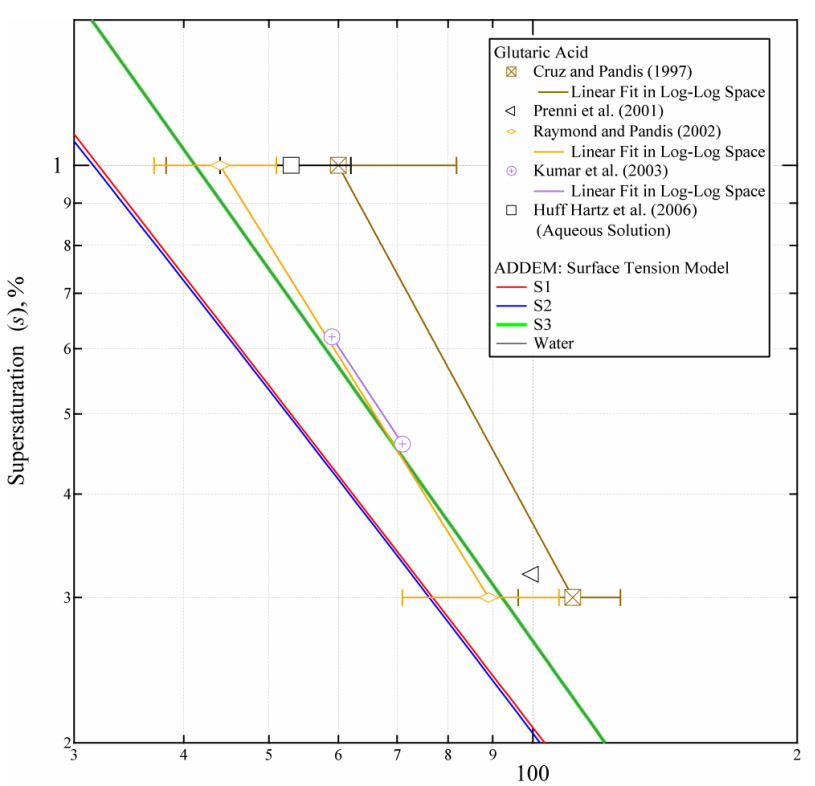

Dry Diameter $\left(D_{\mathrm{p}, \mathrm{dry}}\right), \mathrm{nm}$

(a)

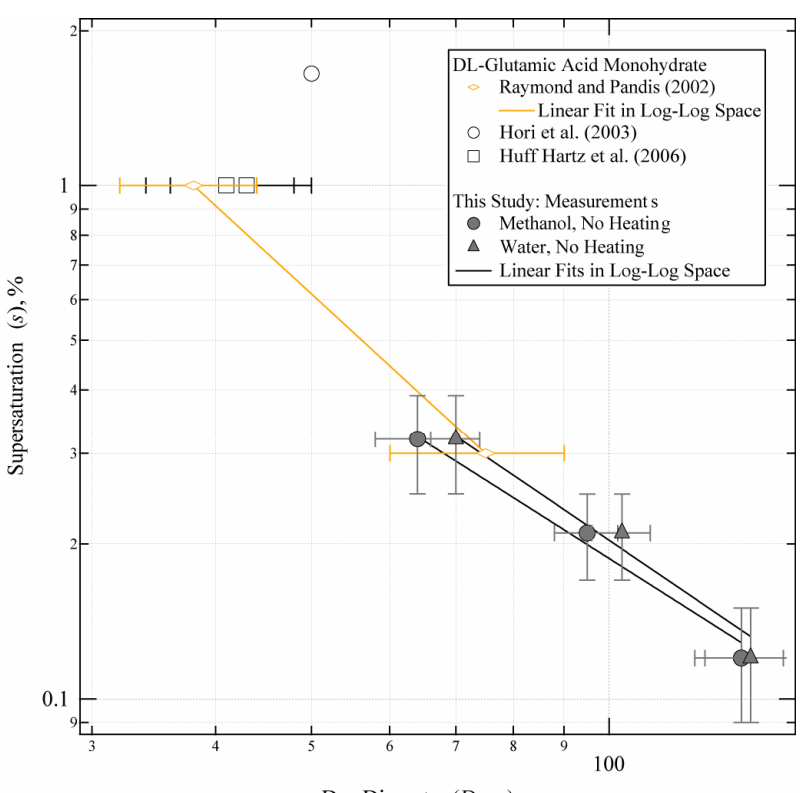

(b)

Fig. 9. Observed and predicted (ADDEM) activation behavior for (a) glutaric acid and (b) DL-glutamic acid monohydrate.

\subsection{Heating after atomization}

In an attempt to vaporize as much solvent as possible from the atomized organic particles, a heater was added after the atomizer but before the driers for experiments with adipic acid, malonic acid, and glutaric acid atomized from both water and aqueous solutions. Size distribution changes were 


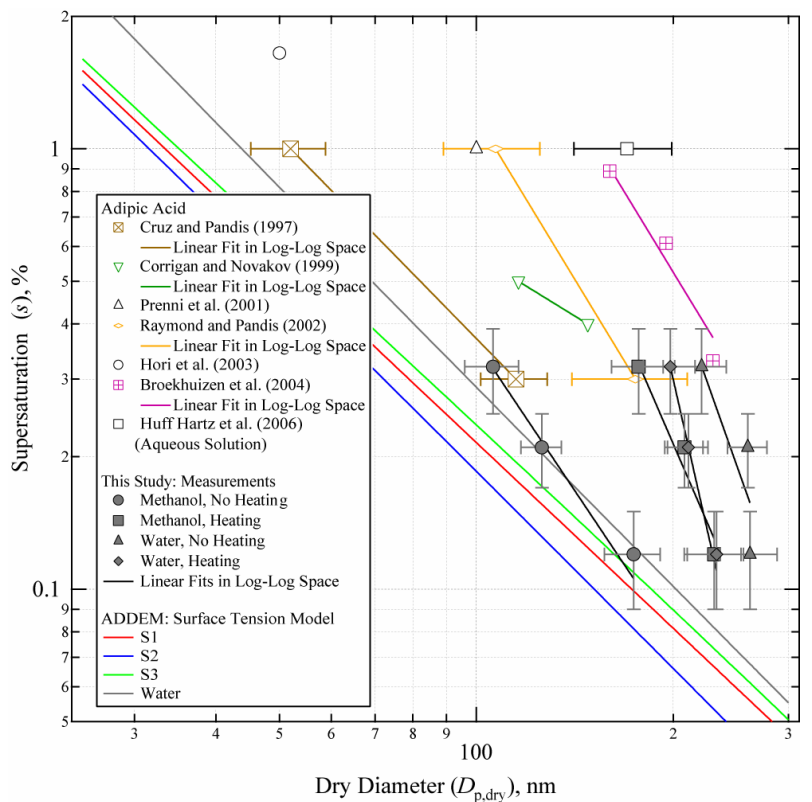

Fig. 10. Observed and predicted (ADDEM) activation behavior for adipic acid.

observed for both malonic acid and glutaric acid, regardless of solvent and the presence of the heater, and CCN data analysis was not performed for these compounds, as was discussed in Sect. 4.1.

With the heater in place, values of $d_{\text {act }}$ decreased for adipic acid/water experiments and increased for adipic acid/methanol at all three operating supersaturations. As discussed in Sect. 3.5.3, the addition of the heater could affect the resulting morphology of the generated particles and, consequently, the size selection in the DMA. Esterification reactions (see Sect. 3.5.4) could also be driven by the presence of heat. Differences observed in the CCN activity for particles atomized in the presence versus absence of the heater could be explained by these phenomena.

\subsection{Compound-specific discussions}

4.4.1 Succinic acid, oxalacetic acid, DL-malic acid, DLglutamic acid monohydrate

The $d_{\mathrm{act}}$ values for particles generated from methanol solutions as compared to aqueous solutions are within measurement errors for succinic acid, oxalacetic acid, DL-glutamic acid, and DL-malic acid (except at $s_{\mathrm{op}}=0.21 \%$ ). Oxalacetic acid exhibited the greatest $\mathrm{CCN}$ activity, near that of ammonium sulfate, at $s_{\mathrm{op}}=0.11 \%$, while succinic acid was the most $\mathrm{CCN}$ active at $s_{\mathrm{op}}=0.21 \%$ and $0.32 \%$. Of these four compounds, DL-glutamic acid monohydrate was the least CCN active at $s_{\mathrm{op}}=0.11 \%$ and $0.21 \%$. DL-malic acid exhibited the lowest CCN activity at $s_{\mathrm{op}}=0.32 \%$. The measured activation diameters for these compounds are within experimental er-

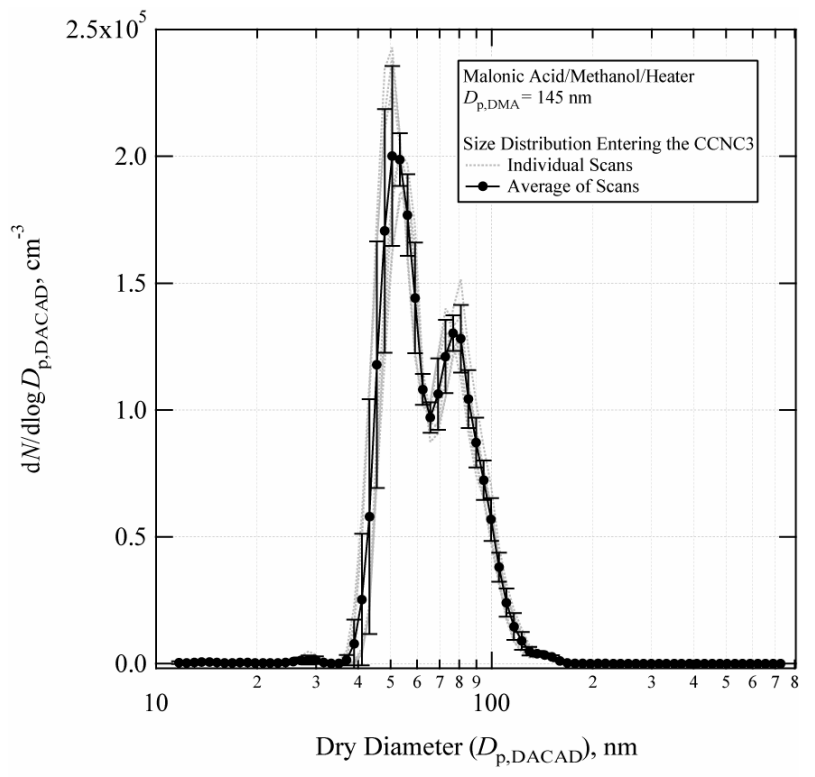

(a)

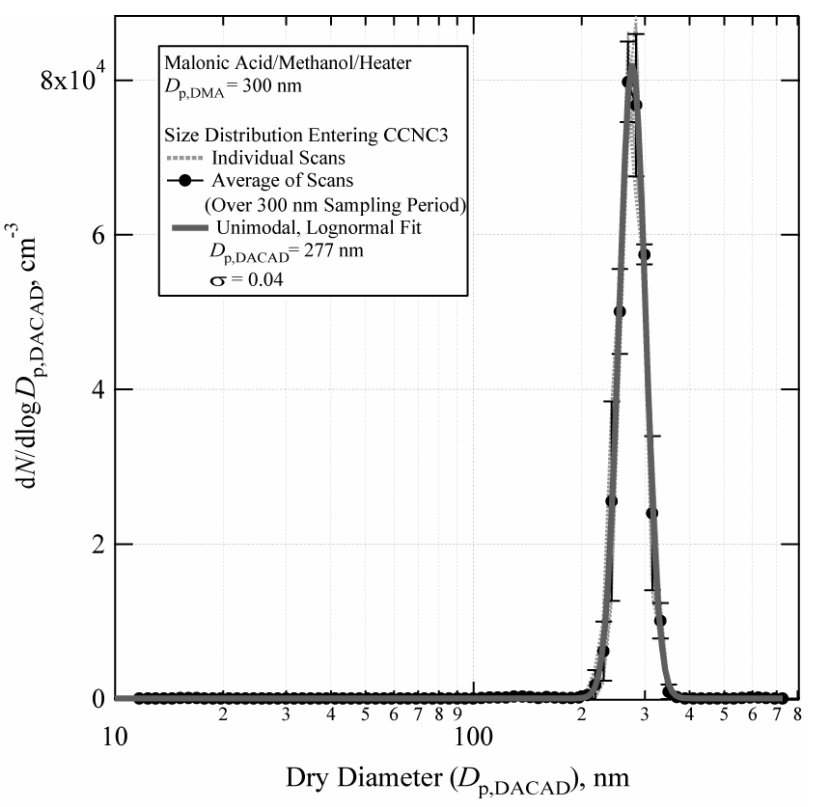

(b)

Fig. 11. DACAD size distributions for DMA size-selected particles with (a) $D_{\mathrm{p}, \mathrm{DMA}}=145 \mathrm{~nm}$ and (b) $D_{\mathrm{p}, \mathrm{DMA}}=300 \mathrm{~nm}$.

ror when compared to each other for all three operating supersaturations. The measured activation diameters for these compounds also compare well for particles generated from both aqueous and methanol solutions, within experimental error, with the ADDEM predictions, which is illustrated in Figs. 7-10. 
Table 6. Ratios of measured or predicted $d_{\text {act }}$ to $d_{\text {act }}$ for $\left(\mathrm{NH}_{4}\right)_{2} \mathrm{SO}_{4}$ for $s_{\mathrm{op}}=0.32 \%$ a

\begin{tabular}{|c|c|c|c|c|c|c|c|c|}
\hline \multirow{3}{*}{ Compound } & \multicolumn{4}{|c|}{ Measured } & \multirow{2}{*}{\multicolumn{4}{|c|}{ Predicted }} \\
\hline & \multicolumn{2}{|c|}{ Water } & \multicolumn{2}{|c|}{ Methanol } & & & & \\
\hline & $\begin{array}{l}\text { No Heater } \\
\left(d_{\mathrm{act}}, \mathrm{nm}\right) \\
\end{array}$ & $\begin{array}{c}\text { Heater } \\
\left(d_{\mathrm{act}}, \mathrm{nm}\right)\end{array}$ & $\begin{array}{l}\text { No Heater } \\
\left(d_{\mathrm{act}}, \mathrm{nm}\right)\end{array}$ & $\begin{array}{c}\text { Heater } \\
\left(d_{\mathrm{act}}, \mathrm{nm}\right)\end{array}$ & $\begin{array}{c}\mathrm{S} 1 \\
\left(d_{\mathrm{act}}, \mathrm{nm}\right) \\
\end{array}$ & $\begin{array}{c}\mathrm{S} 2 \\
\left(d_{\mathrm{act}}, \mathrm{nm}\right) \\
\end{array}$ & $\begin{array}{c}\mathrm{S} 3 \\
\left(d_{\mathrm{act}}, \mathrm{nm}\right) \\
\end{array}$ & $\begin{array}{c}\text { Water } \\
\left(d_{\mathrm{act}}, \mathrm{nm}\right) \\
\end{array}$ \\
\hline Ammonium Sulfate & $\begin{array}{c}1.00 \\
(61 \pm 3)\end{array}$ & $\mathrm{NE}^{\mathrm{b}}$ & $\mathrm{NE}^{\mathrm{b}}$ & $\mathrm{NE}^{\mathrm{b}}$ & $\begin{array}{l}0.96 \\
(60)\end{array}$ & $\begin{array}{l}0.96 \\
(60)\end{array}$ & $\begin{array}{l}0.96 \\
(60)\end{array}$ & $\begin{array}{l}0.98 \\
(60)\end{array}$ \\
\hline Ammonium Bisulfate & $\begin{array}{c}1.02 \pm 0.14 \\
(62 \pm 8)\end{array}$ & $\mathrm{NE}^{\mathrm{b}}$ & $\mathrm{NE}^{\mathrm{b}}$ & $N E^{b}$ & $\begin{array}{l}0.96 \\
(60)\end{array}$ & $\begin{array}{l}0.96 \\
(60)\end{array}$ & $\begin{array}{l}0.95 \\
(60)\end{array}$ & $\begin{array}{l}0.96 \\
(60)\end{array}$ \\
\hline Sodium Chloride & $\begin{array}{c}0.80 \pm 0.10 \\
(49 \pm 6)\end{array}$ & $\mathrm{NE}^{\mathrm{b}}$ & $N E^{b}$ & $N E^{b}$ & $\begin{array}{l}0.77 \\
(47)\end{array}$ & $\begin{array}{l}0.77 \\
(47)\end{array}$ & $\begin{array}{l}0.77 \\
(47)\end{array}$ & $\begin{array}{l}0.77 \\
(47)\end{array}$ \\
\hline Malonic Acid & $\mathrm{ND}^{\mathrm{b}}$ & $\mathrm{ND}^{\mathrm{b}}$ & $\mathrm{ND}^{\mathrm{b}}$ & $\mathrm{ND}^{\mathrm{b}}$ & $\begin{array}{l}1.25 \\
(76)\end{array}$ & $\begin{array}{l}1.15 \\
(70)\end{array}$ & $\begin{array}{l}1.30 \\
(79)\end{array}$ & $\begin{array}{l}1.23 \\
(75)\end{array}$ \\
\hline Succinic Acid & $\begin{array}{c}1.03 \pm 0.11 \\
(63 \pm 6)\end{array}$ & $N E^{b}$ & $\begin{array}{c}1.15 \pm 0.11 \\
(70 \pm 6)\end{array}$ & $N E^{b}$ & $\begin{array}{l}1.21 \\
(74)\end{array}$ & $\begin{array}{l}1.16 \\
(71)\end{array}$ & $\begin{array}{l}1.36 \\
(83)\end{array}$ & $\begin{array}{l}1.36 \\
(83)\end{array}$ \\
\hline Oxalacetic Acid & $\begin{array}{c}1.07 \pm 0.11 \\
(65 \pm 6)\end{array}$ & $N E^{b}$ & $\begin{array}{c}1.23 \pm 0.13 \\
(75 \pm 7)\end{array}$ & $N E^{b}$ & $\mathrm{NM}^{\mathrm{b}}$ & $\mathrm{NM}^{\mathrm{b}}$ & $\mathrm{NM}^{\mathrm{b}}$ & $\mathrm{NM}^{\mathrm{b}}$ \\
\hline DL-Malic Acid & $\begin{array}{c}1.18 \pm 0.11 \\
(72 \pm 6)\end{array}$ & $N E^{b}$ & $\begin{array}{c}1.02 \pm 0.11 \\
(62 \pm 6)\end{array}$ & $N E^{b}$ & $\begin{array}{l}1.18 \\
(72)\end{array}$ & $\begin{array}{l}1.16 \\
(71)\end{array}$ & $\begin{array}{l}1.43 \\
(87)\end{array}$ & $\begin{array}{l}1.43 \\
(87)\end{array}$ \\
\hline Glutaric Acid & $\mathrm{ND}^{\mathrm{b}}$ & $\mathrm{ND}^{\mathrm{b}}$ & $\mathrm{ND}^{\mathrm{b}}$ & $\mathrm{ND}^{\mathrm{b}}$ & $\begin{array}{l}1.20 \\
(73)\end{array}$ & $\begin{array}{l}1.20 \\
(73)\end{array}$ & $\begin{array}{l}1.46 \\
(89)\end{array}$ & $\begin{array}{l}1.46 \\
(89)\end{array}$ \\
\hline DL-Glutamic Acid Monohydrate & $\begin{array}{c}1.15 \pm 0.11 \\
(70 \pm 6)\end{array}$ & $N E^{b}$ & $\begin{array}{c}1.05 \pm 0.11 \\
(64 \pm 6)\end{array}$ & $N E^{b}$ & $\mathrm{NM}^{\mathrm{b}}$ & $\mathrm{NM}^{\mathrm{b}}$ & $\mathrm{NM}^{\mathrm{b}}$ & $\mathrm{NM}^{\mathrm{b}}$ \\
\hline Adipic Acid & $\begin{array}{c}3.62 \pm 0.37 \\
(221 \pm 20)\end{array}$ & $\begin{array}{c}3.25 \pm 0.33 \\
(198 \pm 18)\end{array}$ & $\begin{array}{c}1.74 \pm 0.14 \\
(106 \pm 10)\end{array}$ & $\begin{array}{c}2.90 \pm 0.30 \\
(177 \pm 16)\end{array}$ & $\begin{array}{l}1.23 \\
(75)\end{array}$ & $\begin{array}{l}1.15 \\
(70)\end{array}$ & $\begin{array}{l}1.30 \\
(79)\end{array}$ & $\begin{array}{l}1.52 \\
(93)\end{array}$ \\
\hline
\end{tabular}

\subsubsection{Glutaric acid and malonic acid}

Malonic acid and glutaric acid, dicarboxylic acids with odd carbon numbers (three and five, respectively), are highly soluble in both water and methanol. Besides DL-glutamic acid, malonic and glutaric acids are the only odd carbon chained compounds studied here.

Size distribution changes were observed after size selection in the classification DMA for malonic acid and glutaric acid, with distributions becoming broadened or multipeaked by the time they were measured in the DACAD. Size distribution changes occurred more often for diameters less than about $200 \mathrm{~nm}$, with size distributions remaining sharp at the larger diameters, and were observed for particles atomized from both methanol and aqueous solutions and for heated and non-heated experiments. If the only process occurring was evaporation of organic material from the particles, the DACAD size distribution would be expected to show one, sharp peak at a smaller diameter (as was observed for the other compounds to some extent) because the same-sized particles would evaporate at the same rate. One hypothesis for the formation of the multipeaked size distributions is that solvent was trapped in some of the particles and subsequently "escaped" from those particles between the DMA and DA$\mathrm{CAD} / \mathrm{CCN}$ instruments, effectively causing those particles to "shrink" more than the particles that did not contain solvent at the point of classification. Also, hollow particles created from atomization of these compounds may have collapsed between the size-selection DMA and the DACAD. Another hypothesis is that there was an unexpectedly large number of doubly charged particles present for these compounds. As discussed in Sect. 4.1, the possible presence of some or all of these size-altering processes prevented determination of $d_{\text {act }}$ for malonic acid and glutaric acid within a reasonable degree of scientific certainty. For this reason, $d_{\text {act }}$ is not presented for these compounds. However, ADDEM predictions and measurements from previous studies are presented in Figs. 7a and $9 \mathrm{a}$ for malonic and glutaric acids, respectively.

\subsubsection{Adipic acid}

Of the compounds studied, the greatest variability in $\mathrm{CCN}$ behavior was observed for adipic acid, with the lowest CCN ability exhibited for adipic acid particles atomized from aqueous solution with no heater present and the most facile CCN activation observed for methanol solutions with no heating. The water/heater and methanol/heater experimental $d_{\text {act }}$ values fall between the no heater results and are comparable at $s_{\mathrm{op}}=0.11 \%$. For $s_{\mathrm{op}}=0.21 \%$ and $0.32 \%$, the methanol/heater $d_{\text {act }}$ values are lower than those for water. Adipic acid is more soluble in methanol than in water, and any residual methanol could facilitate particle dissolution. Also, particle morphology could play a role. These phenomenon could explain the observation in this study, that the measured activation diameters for adipic acid are lower 
Table 7. Slopes and intercepts for linear fits of $s=s_{C}$ or $s_{\mathrm{Op}}$ and $d_{\text {act }}$ in $\log$-log space for measurements and predictions.

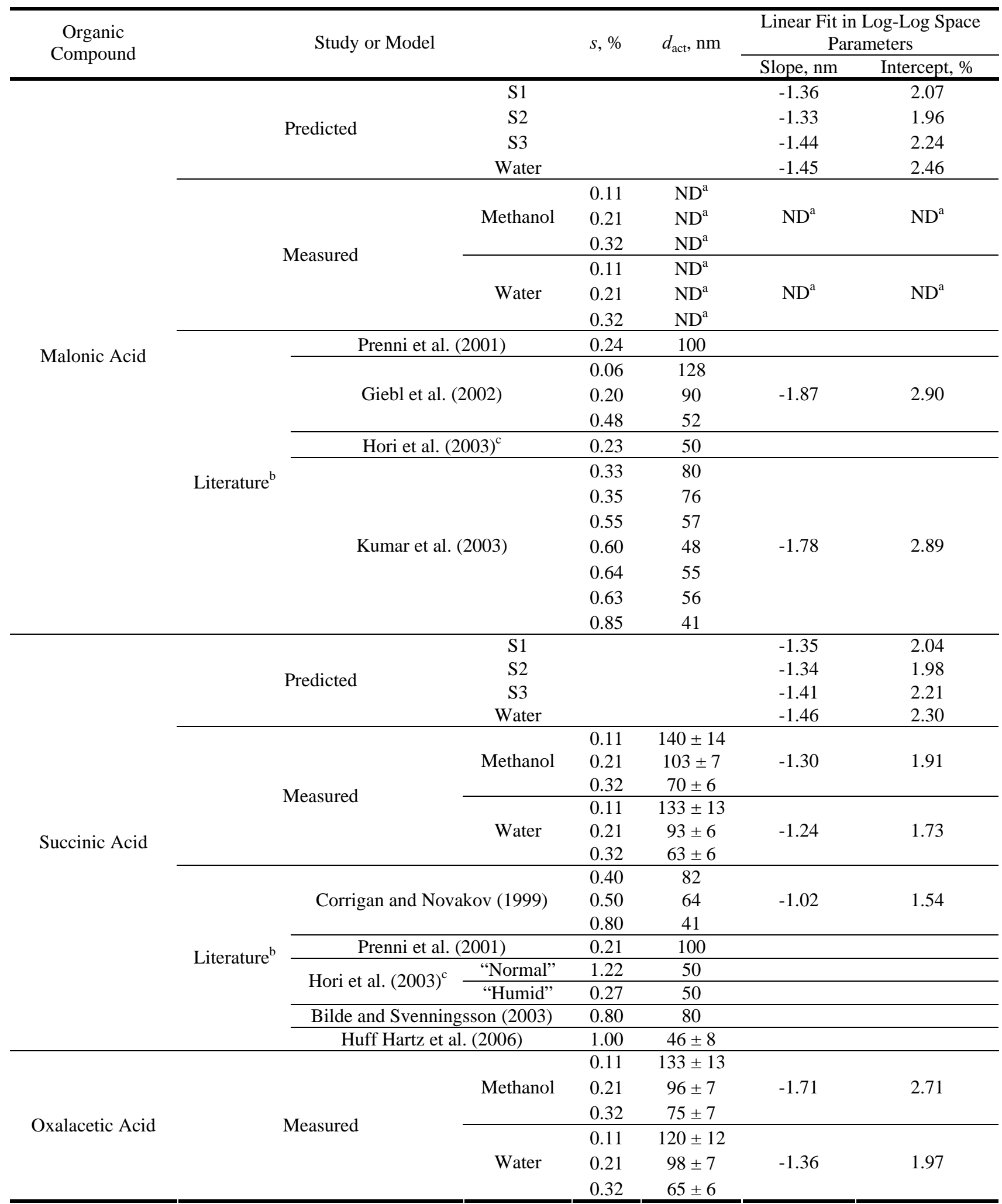

\footnotetext{
a "ND” indicates that these values were "not determined", although experiments were performed.

b "Literature" measured results are for aqueous solutions, unless otherwise specified.

cHori et al. (2003) results are for "humid" conditions, unless otherwise specified.

${ }^{\mathrm{d}}$ Measurements made with the heater for adipic acid are given in parentheses.
} 
Table 7. Continued.

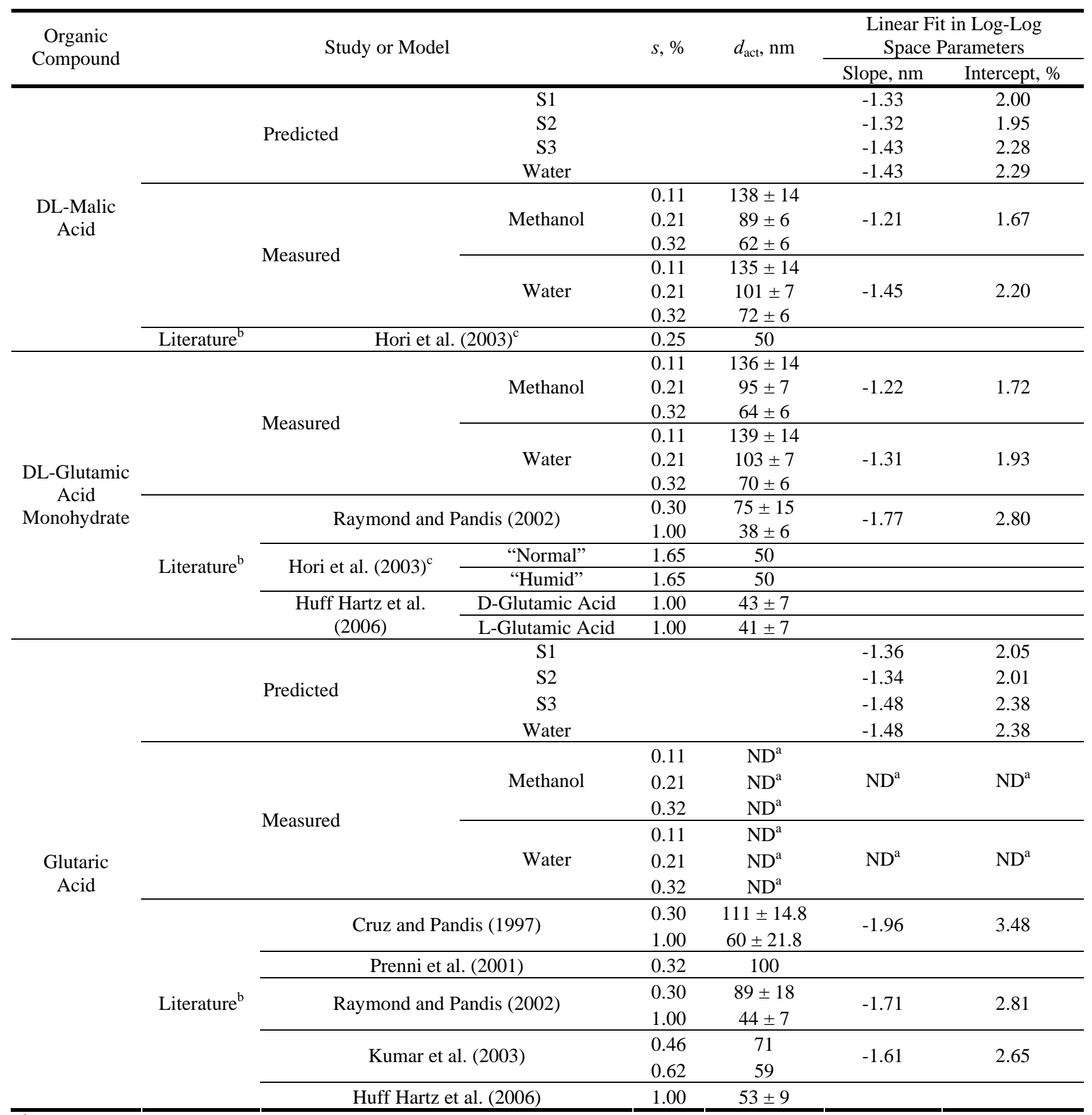

\footnotetext{
a "ND" indicates that these values were "not determined", although experiments were performed.

b "Literature" measured results are for aqueous solutions, unless otherwise specified.

c Hori et al. (2003) results are for "humid" conditions, unless otherwise specified.

${ }^{\mathrm{d}}$ Measurements made with the heater for adipic acid are given in parentheses.
} 
Table 7. Continued.

\begin{tabular}{|c|c|c|c|c|c|c|c|}
\hline \multirow[t]{2}{*}{ Organic Compound } & \multirow{2}{*}{\multicolumn{3}{|c|}{ Study or Model }} & \multirow[t]{2}{*}{$s, \%$} & \multirow[t]{2}{*}{$d_{\mathrm{act}}, \mathrm{nm}$} & \multicolumn{2}{|c|}{$\begin{array}{c}\text { Linear Fit in Log-Log } \\
\text { Space Parameters }\end{array}$} \\
\hline & & & & & & Slope, nm & Intercept, \% \\
\hline \multirow{22}{*}{ Adipic Acid } & \multirow{4}{*}{\multicolumn{2}{|c|}{ Predicted }} & S1 & & & -1.40 & 2.14 \\
\hline & & & S2 & & & -1.43 & 2.14 \\
\hline & & & S3 & & & -1.40 & 2.16 \\
\hline & & & Water & & & -1.53 & 2.51 \\
\hline & \multirow{6}{*}{\multicolumn{2}{|c|}{ Measured $^{\mathrm{d}}$}} & \multirow{3}{*}{$\begin{array}{l}\text { Methanol } \\
\text { (Heater) }\end{array}$} & 0.11 & $\begin{array}{c}174 \pm 17 \\
(231 \pm 23)\end{array}$ & \multirow{3}{*}{$\begin{array}{l}-2.22 \\
(-3.44)\end{array}$} & \multirow{3}{*}{$\begin{array}{c}4.00 \\
(7.24)\end{array}$} \\
\hline & & & & 0.21 & $\begin{array}{c}126 \pm 9 \\
(208 \pm 14)\end{array}$ & & \\
\hline & & & & 0.32 & $\begin{array}{c}106 \pm 10 \\
(177 \pm 16)\end{array}$ & & \\
\hline & & & & 0.11 & $\begin{array}{c}267 \pm 26 \\
(232 \pm 23)\end{array}$ & \multirow{3}{*}{$\begin{array}{l}-4.20 \\
(-6.58)\end{array}$} & \multirow{3}{*}{$\begin{array}{c}9.35 \\
(14.6)\end{array}$} \\
\hline & & & $\begin{array}{l}\text { Water } \\
\text { (Heater) }\end{array}$ & 0.21 & $\begin{array}{c}257 \pm 18 \\
(213 \pm 15)\end{array}$ & & \\
\hline & & & & 0.32 & $\begin{array}{c}221 \pm 20 \\
(198 \pm 18) \\
\end{array}$ & & \\
\hline & \multirow{2}{*}{\multicolumn{3}{|c|}{ Cruz and Pandis (1997) }} & 0.30 & $115 \pm 13.4$ & \multirow{2}{*}{-1.52} & \multirow{2}{*}{2.60} \\
\hline & & & & 1.00 & $52 \pm 6.8$ & & \\
\hline & \multirow{2}{*}{\multicolumn{3}{|c|}{$\begin{array}{c}\text { Corrigan and Novakov } \\
\text { (1999) }\end{array}$}} & 0.40 & 148 & \multirow{2}{*}{-0.92} & \multirow{2}{*}{1.59} \\
\hline & & & & 0.50 & 116 & & \\
\hline & \multirow{8}{*}{ Literature $^{\mathrm{b}}$} & & l. (2001) & 1.00 & 100 & & \\
\hline & & & Ind Pandis & 0.30 & $175 \pm 35$ & \multirow{2}{*}{-2.45} & \multirow{2}{*}{4.97} \\
\hline & & & & 1.00 & $107 \pm 18$ & & \\
\hline & & &.$(2003)^{\mathrm{C}}$ & 1.65 & 50 & & \\
\hline & & \multirow{3}{*}{\multicolumn{2}{|c|}{ Broekhuizen et al. (2004) }} & 0.33 & 230 & \multirow{3}{*}{-2.44} & \multirow{3}{*}{-5.34} \\
\hline & & & & 0.61 & 195 & & \\
\hline & & & & 0.89 & 160 & & \\
\hline & & $\mathrm{Hu}$ & t al. (2006) & 1.00 & $170 \pm 29$ & & \\
\hline
\end{tabular}

(greater CCN activity) for particles generated from methanol solution than those from aqueous solution.

The heater/no heater trends are opposite for adipic acid particles created from aqueous and methanol solutions. With water as the activation solvent, the activation diameters of the adipic acid particles with the heater in place are smaller than those without the heater, but the difference in the activation diameters is not much greater than that expected from experimental error. However, for adipic acid particles created from a methanol solution, the observed activation diameters are greater when the heater is in place. These observations could be a result of differing particle morphology caused by the different solvents and/or the presence of the heater, as discussed. Also, the methanol solvent is expected to be more completely removed from the adipic acid particles when the heater is present. So, some methanol solvent may remain on the particles when the heater is not present and may facilitate the condensation of water onto the adipic acid particles and subsequent droplet activation.

Figure 12 shows the measured $\mathrm{CCN}$ activation curves for adipic acid generated from both water (panels a and $b$ ) and methanol (panels $c$ and d) solutions and with (panels b and d) and without (panels a and c) heating. As shown in the figure, the shape of the $\mathrm{CCN}$ activation curves differs greatly between the experiments. In the absence of heating, the cutoff in the CCN activation curve for adipic acid/water is not as 
Table 8. Measured activation diameters before and after corrections using DACAD measurements.

\begin{tabular}{|c|c|c|c|c|c|c|c|c|c|c|}
\hline \multirow{2}{*}{$\begin{array}{c}\text { Organic } \\
\text { Compound }\end{array}$} & \multirow[t]{2}{*}{ Solvent } & \multicolumn{3}{|c|}{$\begin{array}{l}\text { Uncorrected } d_{\text {act }} \text { Using } \\
D_{\mathrm{p}, \mathrm{dry}}=D_{\mathrm{p}, \mathrm{DMA}}, \mathrm{nm}\end{array}$} & \multicolumn{3}{|c|}{$\begin{array}{l}\text { Corrected } d_{\mathrm{act}} \text { Using } \\
D_{\mathrm{p}, \mathrm{dry}}=D_{\mathrm{p}, \mathrm{DACAD}}, \mathrm{nm}\end{array}$} & \multicolumn{3}{|c|}{$\begin{array}{c}\text { Difference Between } \\
D_{\mathrm{p}, \text { DACAD }} \text { and } D_{\mathrm{p}, \text { DMA }}, \%\end{array}$} \\
\hline & & $s_{\mathrm{op}}=0.11 \%$ & $S_{\mathrm{op}}=0.21 \%$ & $s_{\mathrm{op}}=0.32 \%$ & $s_{\mathrm{op}}=0.11 \%$ & $S_{\mathrm{op}}=0.21 \%$ & $s_{\mathrm{op}}=0.32 \%$ & $s_{\mathrm{op}}=0.11 \%$ & $s_{\mathrm{op}}=0.21 \%$ & $S_{\mathrm{op}}=0.32 \%$ \\
\hline \multirow{2}{*}{$\begin{array}{c}\text { Succinic } \\
\text { Acid }\end{array}$} & Methanol & 148 & 111 & 79 & 140 & 103 & 70 & 6 & 8 & 13 \\
\hline & Water & 139 & 100 & 70 & 133 & 93 & 63 & 5 & 8 & 11 \\
\hline \multirow{2}{*}{$\begin{array}{l}\text { Oxalacetic } \\
\text { Acid }\end{array}$} & Methanol & 144 & 110 & 86 & 133 & 96 & 75 & 8 & 15 & 15 \\
\hline & Water & 125 & 105 & 68 & 120 & 98 & 65 & 4 & 7 & 5 \\
\hline \multirow{2}{*}{$\begin{array}{l}\text { DL-Malic } \\
\text { Acid }\end{array}$} & Methanol & 140 & 97 & 68 & 138 & 89 & 62 & 6 & 6 & 5 \\
\hline & Water & 140 & 105 & 76 & 135 & 101 & 72 & 1 & 9 & 10 \\
\hline \multirow{2}{*}{$\begin{array}{l}\text { DL-Glutamic } \\
\text { Acid } \\
\text { Monohydrate }\end{array}$} & Methanol & 144 & 100 & 68 & 136 & 95 & 64 & 6 & 6 & 5 \\
\hline & Water & 140 & 105 & 76 & 139 & 103 & 70 & 4 & 4 & 6 \\
\hline \multirow{2}{*}{ Adipic Acid } & $\begin{array}{l}\text { Methanol } \\
\text { (Heater) }\end{array}$ & $\begin{array}{c}177 \\
(283)\end{array}$ & $\begin{array}{c}132 \\
(204)\end{array}$ & $\begin{array}{c}113 \\
(175)\end{array}$ & $\begin{array}{c}174 \\
(231)\end{array}$ & $\begin{array}{c}126 \\
(208)\end{array}$ & $\begin{array}{c}106 \\
(177)\end{array}$ & $\begin{array}{c}2 \\
(23)\end{array}$ & $\begin{array}{c}5 \\
(2)\end{array}$ & $\begin{array}{c}7 \\
(1)\end{array}$ \\
\hline & $\begin{array}{c}\text { Water } \\
\text { (Heater) }\end{array}$ & $\begin{array}{c}272 \\
(241) \\
\end{array}$ & $\begin{array}{c}278 \\
(219) \\
\end{array}$ & $\begin{array}{c}175 \\
(224) \\
\end{array}$ & $\begin{array}{r}267 \\
(232) \\
\end{array}$ & $\begin{array}{c}257 \\
(213) \\
\end{array}$ & $\begin{array}{c}221 \\
(198) \\
\end{array}$ & $\begin{array}{c}4 \\
(3) \\
\end{array}$ & $\begin{array}{c}7 \\
(4) \\
\end{array}$ & $\begin{array}{c}1 \\
(4) \\
\end{array}$ \\
\hline
\end{tabular}

sharp as that observed for adipic acid/methanol. This could result from the phenomena that have been discussed previously: solvent residual and particle morphology differences.

With heating, the CCN activation curves for adipic acid collapse onto each other for particles atomized from both water and methanol solutions. The CCN activation curve for the aqueous solution has a sharper cut-off than that for the methanol solution when heating is applied. In fact, the adipic acid/methanol/heater $\mathrm{CCN}$ activation curve is almost linear for all three operating supersaturations until about $200 \mathrm{~nm}$, when it begins to approach $A R=0$ asymptotically. This difference in the shape of the $\mathrm{CCN}$ activation curve could be caused by esterification of adipic acid after atomization but before drying is complete. With the heater in place, the esterification reaction could be facilitated and less hygroscopic ester products would be expected. These experiments were conducted at low RH $(\sim 5 \%)$, which would also favor ester formation in the particle phase. The extent to which esterification occurs may depend also on the size of the particle, so that the extent of esterification is less at larger dry diameters. This would explain the linear structure of the $\mathrm{CCN}$ activation curve for the adipic acid/methanol/heater experiment. For example, at $250 \mathrm{~nm}, A R$ is about 0.82 . This could imply that $82 \%$ of the particles is adipic acid and $18 \%$ (calculated to get a total of $100 \%$ ) are ester derivatives of adipic acid that are not $\mathrm{CCN}$-active at $250 \mathrm{~nm}$ at the operating supersaturations of the $\mathrm{CCN}$ instrument. As dry diameter decreases, the degree of esterification could be increasing. The effect on the CCN activation curve would not be as evident, though, because at these smaller diameters, neither adipic acid nor its less-hygroscopic ester-derivatives would exhibit $\mathrm{CCN}$ activity. Even though it appears that esterification reactions are size dependent, further investigation is warranted. Size-resolved composition measurements should be made to validate this possible effect and until such measurements are made, the size-dependence of esterification reactions remains an unproven hypothesis that could provide an explanation for the observations of this study.
To determine whether esterification reactions are a possible explanation for the adipic acid results, filter samples were taken after the size selection DMA at particle sizes of $300 \mathrm{~nm}, 200 \mathrm{~nm}, 100 \mathrm{~nm}$, and $50 \mathrm{~nm}$. The different sizes were all collected on the same filter, so that size resolution was not obtained. (-)LC/ESI-MS results indicate that most of the sample was indeed adipic acid, with the dominant chromatographic peak having a $[\mathrm{M}-\mathrm{H}]^{-}$ion $(\mathrm{M}$ is defined as the molecular weight of the species) at $m / z 145$ and a retention time similar to that of the adipic acid standard used in the atomization solution. However, two less intense chromatographic peaks were observed, both containing a $[\mathrm{M}-\mathrm{H}]^{-}$ ion at $m / z 159$, which also exhibited greater retention times in the HPLC than adipic acid. The longer retention time is a strong indication that these products are less hygroscopic than adipic acid because solubility, and thus hygroscopicity, increases with decreased retention times in the HPLC. One of these less intense chromatographic peaks at $m / z 159$ had the same retention time and similar mass spectrum to that of an adipic acid monomethyl ester standard. The other less intense chromatographic peak at $m / z 159$ had the same retention time as a pimelic acid standard; however, it is possible that this peak is an isomer of the adipic acid monomethyl ester due to the mass spectrum not closely matching that of the pimelic acid standard. Joutsensaari et al. (2004) studied the growth behavior of adipic acid particles in ethanol vapor with an organic tandem differential mobility analyzer (OTDMA) technique and did not observe evidence of esterification reactions. However, their conclusions are based on measured growth curves and not necessarily on chemical analysis. Also, the measurements presented here were performed with heating and at low RH, which could drive the esterification reaction beyond what was observed by Joutsensaari et al. (2004).

Discrepancies between the ADDEM predictions and the measured activation diameters are greatest for adipic acid. Although the results for adipic acid particles generated from a methanol solution without the heater fall nicely within the 


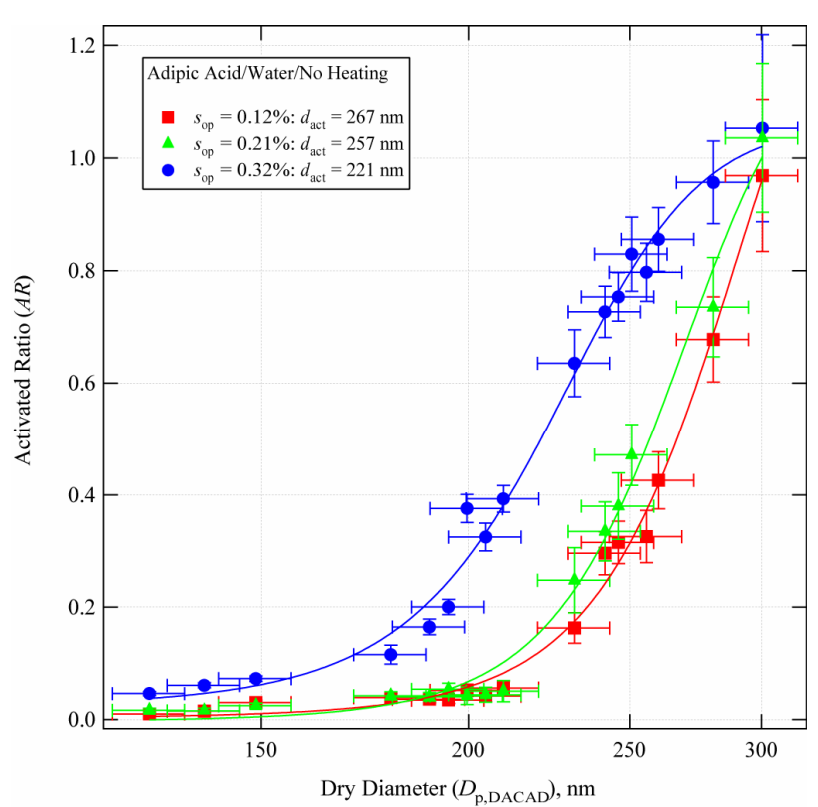

(a)

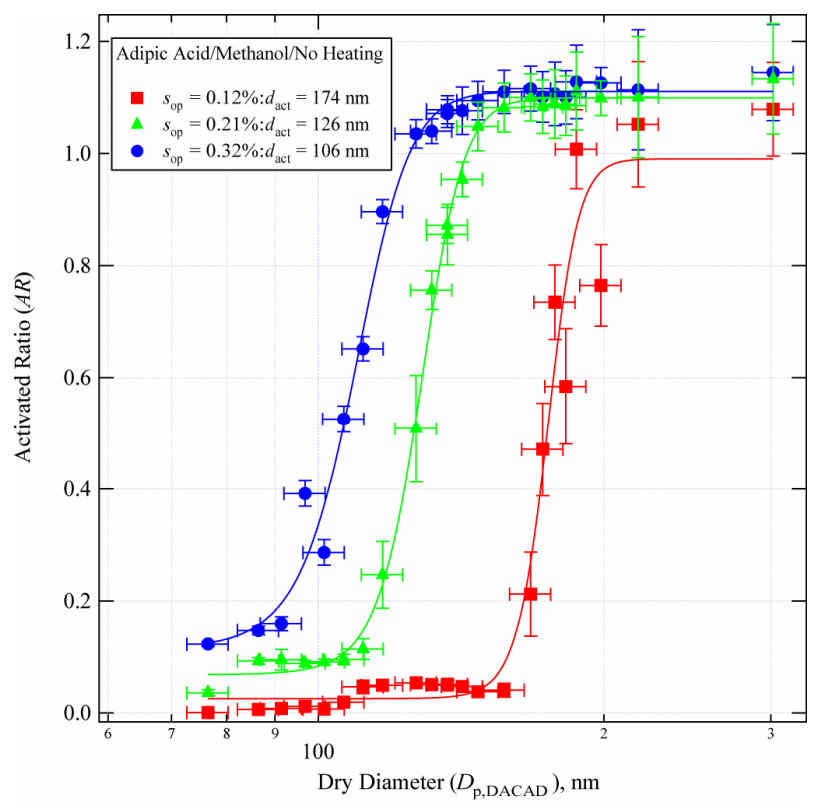

(c)

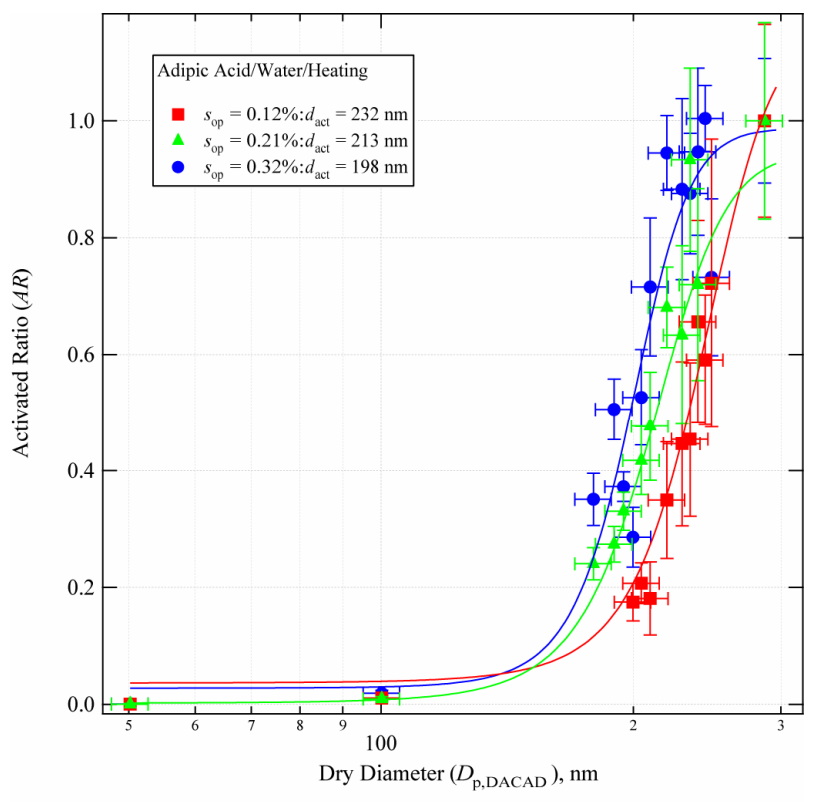

(b)

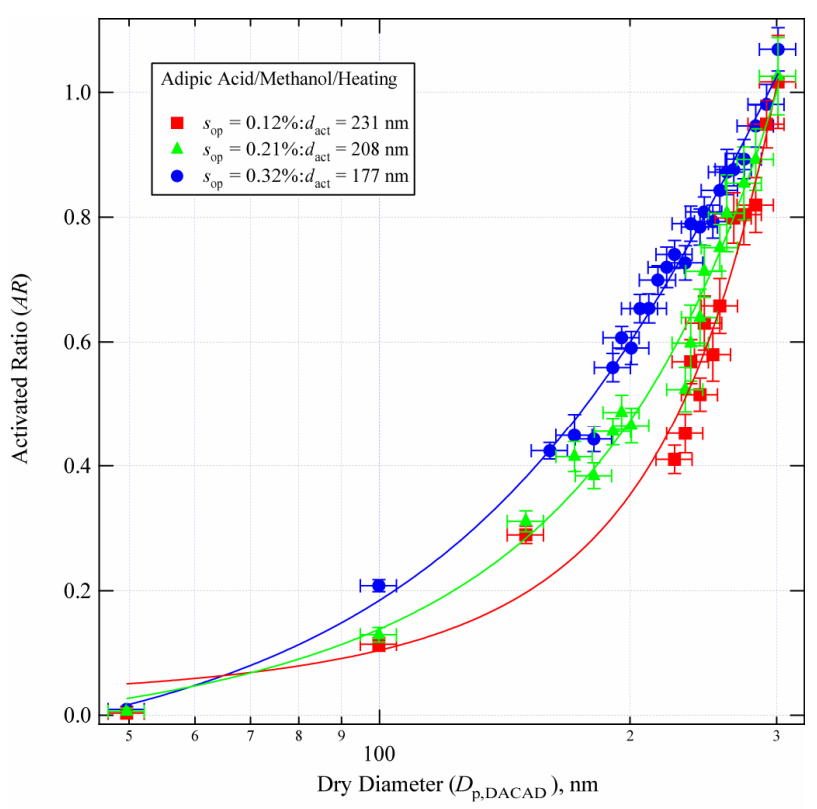

(d)

Fig. 12. CCN activation curves for adipic acid for (a) water/no heating, (b) water/heating, (c) methanol/no heating, and (d) methanol/heating.

ADDEM predictions, this agreement could be coincidental. Differences between ADDEM predictions for the various surface tension models and the scatter in data from past studies are greatest for adipic acid, as well. This reinforces the findings of this study, in which the adipic acid results vary greatly and prevent conclusions about the actual CCN activity of adipic acid.

\section{Conclusions}

Organic compound $\mathrm{CCN}$ experiments have been carried out, in which the effects of atomization solution and the presence of heating after atomization were studied. For most of the compounds and operating supersaturations studied, the choice of solvent did not result in statistically significant differences in the measured activation diameters. However, for adipic acid, the measured activation diameters were 
significantly different, depending on the solvent used for atomization. Particle morphology, incomplete drying, and presence of esterification reactions could explain the effects on $\mathrm{CCN}$ activity observed with different atomization solvents.

Changes in size distribution were observed for malonic acid and glutaric acid between the size classification DMA and the CCNC3/DACAD inlets, and shrinking of the other compounds between size selection and $\mathrm{CCNC} 3$ measurements was observed in some cases. If the DACAD had not been utilized, these effects would not have been observed and misleading results would have been obtained.

Adipic acid was especially sensitive to the choice of solvent and the presence of heating. It is likely that esterification reactions occurred during atomization of adipic acid from methanol solutions when heat was added, as is suggested by filter results. Particle morphology and incomplete drying could also explain the differences observed between the atomization solvents and the presence and absence of heating.

Considering that these effects are observed strongly in a laboratory setting, it is highly possible that these effects are also relevant in the atmosphere; the way in which an organic particle is formed could affect its ambient CCN activation behavior. Properties such as morphology and particle phase can depend heavily on particle origin and the conditions under which a particle is formed, including RH and temperature. These formation conditions can, in turn, affect a particle's CCN behavior. It is important to identify possible biases inherent to the generation of aerosol particles and the subsequent $\mathrm{CCN}$ measurements in a laboratory setting. Such biases must be taken into careful consideration to properly interpret $\mathrm{CCN}$ experimental results.

Acknowledgements. The authors would like to thank F. J. Brechtel, J. H. Kroll, A. Nenes, and A. P. Olsen for helpful suggestions and comments, M. C. Facchini, G. Kiss, and S. Decesari for experimental surface tension data for the ADDEM, and H. Gates for DACAD flow calibrations. The authors would also like to thank B. Svenningsson for her helpful and insightful comments. This work was supported by National Science Foundation grant ATM-0340832.

Edited by: A. Laaksonen

\section{References}

Angove, D. E., Fookes, C. J. R., Hynes, R. G., Walters, C. K., and Azzi, M.: The characterization of secondary organic aerosol formed during the photodecomposition of 1,3-butadiene in air containing nitric oxide, Atmos. Environ., 40, 4597-4607, 2006.

Barsanti, K. C. and Pankow, J. F.: Thermodynamics of the formation of atmospheric particulate matter by accretion reactions Part 3: Carboxylic acids and dicarboxylic acids, Atmos. Environ., 40, 6676-6686, 2006.
Bilde, M. and Svenningsson, B.: CCN activation of slightly soluble organics: The importance of small amounts of inorganic salt and particle phase, Tellus, 56B, 128-134, 2003.

Biskos, G., Russell, L. M., Buseck, P. R., and Martin, S. T.: Nanosize effect on the hygroscopic growth factor of aerosol particles, Geophys. Res. Lett., 33, L07801, doi:10.1029/2005GL025199, 2006.

Brent, R., Winograd, S., and Wolfe, P.: Optimal iterative processes for root-finding, Numer. Mathe., 20, 327-341, 1973.

Broekhuizen, K., Kumar, P. P., and Abbatt, J. P. D.: Partially soluble organics as cloud condensation nuclei: Role of trace soluble and surface active species, Geophys. Res. Lett., 31, L01107, doi:10.1029/2003GL018203, 2004.

Buckingham, J. and Macdonald, F.: Dictionary of Organic Compounds, Chapman \& Hall/CRC Press, London, UK, 1995.

Chen, J. P.: Theory of deliquescence and modified Köhler Curves, J. Atmos. Sci., 51, 3505-3516, 1994.

Clegg, S. L., Pitzer, K. S., and Brimblecombe, P.: Thermodynamics of multicomponent, miscible, ionic solutions. 2. Mixtures including unsymmetrical electrolytes, J. Phys. Chem., 96, 9470-9479, 1992.

Corrigan, C. E. and Novakov, T.: Cloud condensation nucleus activity of organic compounds: A laboratory study, Atmos. Environ., 33, 2661-2668, 1999.

Cruz, C. N. and Pandis, S. N.: A study of the ability of pure secondary organic aerosol to act as cloud condensation nuclei, Atmos. Environ., 31, 2205-2214, 1997.

DeCarlo, P. F., Slowik, J. G., Worsnop, D. R., Davidovits, P., and Jimenez, J. L.: Particle morphology and density characterization by combined mobility and aerodynamic diameter measurements. Part 1: Theory, Aerosol Sci. Technol., 1185-1205, 2004.

Edney, E. O., Kleindienst, T. E., Jaoui, M., Lewandowski, M., Offenberg, J. H., Wang, W., and Claeys, M.: Formation of 2-methyl tetrols and 2-methylglyceric acid in secondary organic aerosol from laboratory irradiated isoprene/ $/ \mathrm{NO}_{X} / \mathrm{SO}_{2} /$ air mixtures and their detection in ambient $\mathrm{PM}_{2.5}$ samples collected in the eastern United States, Atmos. Environ., 39, 5281-5289, 2005.

Fredenslund, A., Jones, R. L., and Prausnitz, J. M.: Groupcontribution estimation of activity-coefficients in nonideal liquid-mixtures, AIChE J., 21, 1086-1099, 1975.

Gao, S., Keywood, M. , Ng, N. L., Surratt, J., Varutbangkul, V., Bahreini, R., Flagan, R. C., and Seinfeld, J. H.: Low-molecular weight and oligomeric components in secondary organic aerosol from the ozonolysis of cycloalkenes and $\alpha$-pinene, J. Phys. Chem., 108, 10 147-10 164, 2004.

Gao, S., Surratt, J. D., Knipping, E. M., Edgerton, E. S., Shahgholi, M., and Seinfeld, J. H.: Characterization of polar organic components in fine aerosols in the Southeastern United States: Identity, origin, and evolution, J. Geophys. Res., 111, D14314, doi:10.1029/2005JD006601, 2006.

Giebl, H., Berner, A., Reischl, G., Puxbaum, H., Kasber-Giebl, A., and Hitzenberger, R.: CCN activation of oxalic and malonic test aerosols with the University of Vienna cloud condensation nuclei counter, J. Aerosol Sci., 33, 1623-1634, 2002.

Heintzenberg, J.: Fine particles in the global troposphere, A review, Tellus, 41B, 149-160, 1989.

Henning, S., Rosenørn, T., D’ Anna, B., Gola, A. A., Svenningsson, B., and Bilde, M.: Cloud droplet activation and surface tension of mixtures of slightly soluble organics and inorganic salt, Atmos. 
Chem. Phys., 5, 575-582, 2005,

http://www.atmos-chem-phys.net/5/575/2005/.

Hinds, W. C.: Aerosol Technology: Properties, Behavior, and Measurement of Airborne Particles, 483 pp., John Wiley \& Sons, Inc., New York City, NY, 1999.

Hori, M., Ohta, S., Murao, N., and Yamagata, S.: Activation capability of water soluble organic substances as CCN, J. Aerosol Sci., 34, 419 - 448, 2003.

$\mathrm{Hu}$, Y. F. and Lee, H.: Prediction of the surface tension of mixed electrolyte solutions based on the equation of Patwardhan and Kumar and the fundamental Butler equations, J. Coll. Inter. Sci., 269, 442-448, 2004.

Huff Hartz, K. E., Tischuk, J. E., Chan, M. N., Chan, C. K., Donahue, N. M., and Pandis, S. N.: Cloud condensation nuclei activation of limited solubility organic aerosol, Atmos. Environ., 40, 605-617, 2006.

Intergovernmental Panel on Climate Change (IPCC): Climate Change 2001: The Scientific Basis, Cambridge University Press, Cambridge, UK, 2001.

Iskandar, F., Gradon, L., and Okuyama, K.: Control of the morphology of nanostructured particles prepared by the spray drying of a nonparticle sol, J. Col. Interf. Sci., 265, 396-303, 2003.

Joutsensaari, J., Toivonen, T., Vaattovaara, P., Vesterinen, M., Vepsäläinen, J., and Laaksonen, A.: Time-resolved growth behavior of acid aerosols in ethanol vapor with a tandem-DMA technique, J. Aeros. Sci., 35, 851-867, 2004.

Kalberer, M., Paulsen, D., Sax, M., Steinbacher, M., Dommen, J., Prevot, A. S. H., Fisseha, R., Weingartner, E., Frankevich, V., Zenobi, R., and Baltensperger, U.: Identification of polymers as major components of atmospheric organic aerosols, Science, 303, 1659-1662, 2004.

Koehler, K. A., Kreidenweis, S. M., DeMott, P. J., Prenni, A. J., Carrico, C. M., Ervens, B., and Feingold, G.: Water activity and activation diameters from hygroscopicity data - Part II: Application to organic species, Atmos. Chem. Phys., 5, 10 881-10924, 2005.

Köhler, H.: The nucleus in and the growth of hygroscopic droplets, Trans. Far. Soc., 32, 1152-1161, 1936.

Kumar, P. P., Broekhuizen, K., and Abbatt, J. P. D.: Organic acids as cloud condensation nuclei: Laboratory studies of highly soluble and insoluble species, Atmos. Chem. Phys., 3, 509-520, 2003, http://www.atmos-chem-phys.net/3/509/2003/.

Lide, D. R.: CRC Handbook of Chemistry and Physics, 84th Edition, CRC Press, FL, 2003.

Lide, D. R.: Properties of Organic Compounds: Web Version, Chapman and Hall/CRC Press, http://www.chemnetbase.com/ Scripts/pocweb.exe, 2000.

Li, Z. B. and Lu, B. C. Y.: Surface tension of aqueous electrolyte solutions at high concentrations - Representation and prediction, Chem. Eng. Sci., 56, 2879-2888, 2000.

McFiggans, G., Artaxo, P., Baltensperger, U., Coe, H., Facchini, M. C., Feingold, G., Fuzzi, S., Gysel, M., Laaksonen, A., Lohmann, U., Mentel, T. F., Murphy, D. M., O’Dowd, C. D., Snider, J. R., and Weingartner, E.: The effect of physical and chemical aerosol properties on warm cloud droplet activation, Atmos. Chem. Phys., 6, 2593-2649, 2006,

http://www.atmos-chem-phys.net/6/2593/2006/.

Novakov, T. and Penner, J. E.: Large contributions of organic aerosols to cloud-condensation nuclei concentrations, Nature,
365, 823-825, 1993.

O’Neil, M. J., Smith, A., and Heckelman, P. E.: The Merck IndexAn Encyclopedia of Chemicals, Drugs, and Biologicals. 13th Edition, Merck \& Co., Inc., New Jersey, 2001.

Peng, C., Chan, M. N., and Chan, C. K.: The hygroscopic properties of dicarboxylic acids: Measurements and UNIFAC predictions, Environ. Sci. Technol., 35, 4495-4501, 2001.

Pitzer, K. S. and Simonson, J. M.: Thermodynamics of multicomponent, miscible, ionic systems: Theory and equations, J. Phys. Chem., 90, 3005-3009, 1986.

Prenni, A. J., DeMott, P. J., Kreidenweis, S. M., Sherman, D. E., Russell, L. M., and Ming, Y.: The effects of low molecular weight dicarboxylic acids on cloud formation, J. Phys. Chem., 105, 11 240-11 248, 2001.

Press, W. H., Teukolsky, S. A., Vetterling, W. T., and Flannery, B. P.: Numerical recipes in Fortran 77: The art of scientific computing, Cambridge University Press, Cambridge, U.K., 1992.

Raymond, T. M. and Pandis, S. N.: Cloud activation of singlecomponent organic aerosol particles, J. Geophys. Res., 107, 4787, doi:10.1029/2002JD002159, 2002.

Rissman, T. A., Nenes, A., and Seinfeld, J. H.: Chemical amplification (or dampening) of the Twomey Effect: Conditions derived from droplet activation theory, J. Atmos. Sci., 61, 919-930, 2004.

Rissman, T. A., VanReken, T. M., Wang, T. M., Gasparini, R., Collins, D. R., Jonsson, H. H., Brechtel, F. J., Flagan, R. C., and Seinfeld, J. H.: Characterization of ambient aerosol from measurements of cloud condensation nuclei during the 2003 Atmospheric Radiation Measurement Aerosol Intensive Observational Period at the Southern Great Plains site in Oklahoma, J. Geophys. Res., 111, D05S11, doi:10.1029/2004JD005695, 2006.

Rudich, Y:: Laboratory perspectives on the chemical transformations of organic matter in atmospheric particles, Chem. Rev., 103, 5097-5124, 2003.

Saxena, P. and Hildeman, L. M.: Water-soluble organics in atmospheric particles: a critical review of the literature and application of thermodynamics to identify candidate compounds, J. Atmos. Chem., 24, 57-109, 1996.

Seinfeld, J. H. and Pandis, S. N.: Atmospheric Chemistry: From Air Pollution to Climate Change, Second Edition, John Wiley \& Sons, Inc., New York City, NY, 2006.

Suarez, J. T., Torresmarchal, C., and Rasmussen, P.: Prediction of surface tensions of nonelectrolyte solutions, Chem. Eng. Sci., 44, 782-786, 1989.

Sun, J. and Ariya, P. A.: Atmospheric organic and bio-aerosols as cloud condensation nuclei $(\mathrm{CCN})$ : A review, Atmos. Environ., 40, 795-820, 2006.

Surratt, J. D., Murphy, S. M., Kroll, J. H., Ng, N. L., Hildebrandt, L., Sorooshian, A., Szmigielski, R., Vermeylen, R., Maenhaut, W., Claeys, M., Flagan, R. C., and Seinfeld, J. H.: Chemical composition of secondary organic aerosol formed from the photooxidation of isoprene, J. Phys. Chem., 110, 9665-9690, 2006.

Szmigielski, R., Surratt, J. D., Vermeylen R., Szmigielska, K., Kroll, J. H., Ng, N. L., Murphy, S. M., Sorooshian, A., Seinfeld, J. H., and Claeys M.: Characterization of 2-methylglyceric acid oligomers in secondary organic aerosol formed from the photooxidation of isoprene using trimethylsilylation and gas chromatography / ion trap mass spectrometry, J. Mass. Spectrom, 42, 101-116, 2007.

Tamura, M., Kurata, M., and Odani, H.: Practical method for esti- 
mating surface tensions of solutions, Bull. Chem. Soc. Japan, 28, 83-88, 1955.

Topping, D. O., McFiggans, G. B., and Coe, H.: A curved multicomponent aerosol hygroscopicity model framework: Part 1 - Inorganic compounds, Atmos. Chem. Phys., 5, 1205-1222, 2005a.

Topping, D. O., McFiggans, G. B., and Coe, H.: A curved multicomponent aerosol hygroscoplicity model framework: Part $2-$ Including organic compounds, Atmos. Chem. Phys., 5, 12231242, 2005b.

VanReken, T. M., Rissman, T. A., Roberts, G. C., Varutbangkul, V., Jonsson, H. H., Flagan, R. C., and Seinfeld, J. H.: Toward aerosol/cloud condensation nuclei (CCN) closure during CRYSTAL-FACE, J. Geophys. Res., 108, 4633, doi:10.1029/2003JD003582, 2003.

Wade, L. G.: Organic Chemistry, Prentice Hall, NJ, 1995.
Wang, J., Flagan, R. C., Seinfeld, J. H., Jonsson, H. H., Collins, D. R., Russell, P. B., Schmid, B., Redemann, J., Livingston, J. M., Gao, S., Hegg, D. A., Welton, E. J., and Bates, D.: Clearcolumn radiative closure during ACE-Asia: Comparison of multiwavelength extinction derived from particle size and composition with results from Sun photometry, J. Geophys. Res., 107, 4688, doi:10.1029/2002JD002465, 2002.

Wang, J., Flagan, R. C., and Seinfeld, J. H.: A Differential Mobility Analyzer (DMA) system for submicron aerosol measurements at ambient relative humidity, Aerosol Sci. Technol., 37, 46-52, 2003.

Wang, S. C. and Flagan, R. C.: Scanning electrical mobility spectrometer, Aerosol Sci. Technol., 35, 718-727, 1990.

Weast, R. C. and Astle, M. J.: CRC Handbook of Data on Organic Compounds, CRC Press, FL, 1985. 